\title{
New water fractions and transit time distributions at Plynlimon, Wales, estimated from stable water isotopes in precipitation and streamflow
}

\author{
Julia L. A. Knapp ${ }^{1}$, Colin Neal ${ }^{2}$, Alessandro Schlumpf ${ }^{3}$, Margaret Neal ${ }^{2}$, and James W. Kirchner ${ }^{1,3,4}$ \\ ${ }^{1}$ Department of Environmental Systems Science, ETH Zurich, 8092 Zurich, Switzerland \\ ${ }^{2}$ Centre for Ecology and Hydrology, Wallingford, OX10 8BB, UK \\ ${ }^{3}$ Swiss Federal Research Institute WSL, 8903 Birmensdorf, Switzerland \\ ${ }^{4}$ Department of Earth and Planetary Science, University of California, Berkeley, CA 94720, USA
}

Correspondence: Julia L. A. Knapp (julia.knapp@usys.ethz.ch)

Received: 7 June 2019 - Discussion started: 12 June 2019

Revised: 4 September 2019 - Accepted: 11 September 2019 - Published: 28 October 2019

\begin{abstract}
Long-term, high-frequency time series of passive tracers in precipitation and streamflow are essential for quantifying catchment transport and storage processes, but few such data sets are publicly available. Here we describe, present, and make available to the public two extensive data sets of stable water isotopes in streamflow and precipitation at the Plynlimon experimental catchments in central Wales. Stable isotope data are available at 7-hourly intervals for 17 months, and at weekly intervals for 4.25 years. Precipitation isotope values were highly variable in both data sets, and the high temporal resolution of the 7-hourly streamwater samples revealed rich isotopic dynamics that were not captured by the weekly sampling.

We used ensemble hydrograph separation to calculate new water fractions and transit time distributions from both data sets. Transit time distributions estimated by ensemble hydrograph separation were broadly consistent with those estimated by spectral fitting methods, suggesting that they can reliably quantify the contributions of recent precipitation to streamflow. We found that on average, roughly $3 \%$ of streamwater was made up of precipitation that fell within the previous $7 \mathrm{~h}$, and $13 \%-15 \%$ of streamwater was made up of precipitation that fell within the previous week. The contributions of recent precipitation to streamflow were highest during large events, as illustrated by comparing new water fractions for different discharges and precipitation rates. This dependence of new water fractions on water fluxes was also reflected in their seasonal variations, with lower new water
\end{abstract}

fractions and more damped catchment transit time distributions in spring and summer compared to fall and winter.

We also compared new water fractions obtained from stable water isotopes against those obtained from concentrations of chloride, a solute frequently used as a passive tracer of catchment transport processes. After filtering the chloride data for dry deposition effects, we found broadly similar new water fractions using chloride and stable water isotopes, indicating that these different tracers may yield similar inferences about catchment storage and transport, if potentially confounding factors are eliminated.

These stable isotope time series comprise some of the longest and most detailed publicly available catchment isotope data sets. They complement extensive solute data sets that are already publicly available for Plynlimon, enabling a wide range of future analyses of catchment behavior.

\section{Introduction}

Passive tracers have frequently been used to understand transport and mixing processes at the catchment scale. Because the tracers do not react strongly with their environment, but instead are transported with the water, their time series in streamflow and precipitation can be compared to estimate transit time distributions and timescales of catchment storage (Christophersen and Neal, 1990; Hrachowitz et al., 2009). Due to the cost and effort involved in col- 
lecting and analyzing environmental tracers, available data sets typically comprise either short series of high-frequency measurements, or longer series of lower-frequency measurements. High-frequency tracer time series measured over a few days to weeks can help in understanding storage, mixing and transport processes during individual storm events, and how these change with factors such as precipitation intensity and catchment wetness (e.g., Casper et al., 2003; James and Roulet, 2009; Segura et al., 2012). Conversely, tracer measurements covering several seasons or years at weekly or bi-weekly resolution can help in understanding interseasonal changes in storage, long-term effects of disturbance events, and implications of climate and land-use change (e.g., McGuire et al., 2002; Heidbüchel et al., 2013).

Few catchment tracer time series are publicly available. This is particularly true for time series of stable water isotopes, which are nearly ideal passive tracers because they are part of the water molecule itself. Among the few longterm time series that are publicly available, for example, are isotope measurements taken biweekly from 2006 to 2010 at Hubbard Brook Watershed 3 (Campbell and Green, 2019). Stable water isotope time series are also publicly available for many sites worldwide through the Global Network of Isotopes in Precipitation (GNIP) and Global Network of Isotopes in Rivers (GNIR), both hosted by the International Atomic Energy Agency (IAEA, 2019; IAEA/WMO, 2019). These time series, however, mostly consist of only a few samples and often have large gaps.

If we want to exploit the full potential of stable isotopes to trace flowpaths and quantify travel times, we need to sample them at much higher than weekly frequencies, because the variations in the water fluxes as drivers of the underlying processes need to be reflected in the sampling. This requires longer-term, higher-frequency records than are currently available. Because similar records of stable water isotopes are scarce, many analyses of catchment transport, storage, and mixing have used anion tracers like chloride instead (e.g., Duffy and Gelhar, 1986; Kirchner et al., 2000; Hrachowitz et al., 2009; Remondi et al., 2018). This raises the obvious question of whether analyses of chloride and isotope tracers yield comparable results (Neal and Rosier, 1990; Kirchner et al., 2010), as each tracer suffers from its own shortcoming. Stable water isotopes suffer from evaporative fractionation, which may be inconsequential if the soil water and precipitation fractionated by evaporation is subsequently evaporated completely but may substantially affect analyses of catchment processes if the fractionated water constitutes a non-trivial fraction of stream discharge. Stable water isotope data also need to be corrected for altitude effects if the precipitation sampling point is not representative of the average catchment elevation (Dansgaard, 1961; Clark and Fritz, 2013). Unlike stable water isotopes, chloride concentrations can be affected by dry deposition between rain events. These dry deposition inputs and their effect on the catchment input-output relationship are difficult to mea- sure and quantify (Juang and Johnson, 1967; Durand et al., 1994; Guan et al., 2010). Furthermore, chloride may be affected by evapoconcentration, undergo ion exchange buffering, and interact biogeochemically with vegetation and soils (Öberg, 2002; Lovett et al., 2005; Bastviken et al., 2007). In some catchments, anthropogenic contamination with chloride from road salt or fertilizers may also be substantial. Thus chloride is most useful as a tracer where sea salt inputs are high enough, and variable enough, to overwhelm these potentially confounding factors. Stable water isotopes, on the other hand, will be most useful where the isotopic input signals are highly variable over time, due to catchment inputs alternating among isotopically distinct source regions and atmospheric pathways with varying degrees of Rayleigh distillation.

Because they are shaped by different processes, atmospheric inputs of chloride and water isotopes are only weakly correlated and follow very different distributions. Thus direct comparisons of chloride and water isotope time series are not informative. However, both tracers should yield similar inferences about catchment storage, transport, and mixing, if they are both transported conservatively with the water. In this context, Kirchner et al. (2010) found that power spectra for both tracers exhibited similar patterns of fluctuation damping from precipitation to streamwater, but the damping was stronger for oxygen- 18 than chloride.

In this paper we document, present, and make available to the public two extensive data sets of stable water isotope time series recorded in precipitation and streamwater at the intensively studied Plynlimon experimental catchments in Wales; one at weekly resolution for 4.25 years, and the other one at 7-hourly intervals for 17 months. We present details of these data sets and their collection and analysis. For both data sets, associated solute data sets are already available, spanning a range of solutes including chloride (Neal et al., 2013c, b; Norris et al., 2017).

We furthermore use these isotope time series to quantify the relative amount of streamflow that is made up of recent precipitation, by applying the recently developed "ensemble hydrograph separation" approach of Kirchner (2019). This approach assesses catchment transport and mixing processes by quantifying, directly from measured data, the fraction of streamwater that fell as precipitation during the last sampling interval. This "new water fraction" has previously been validated through benchmark testing with synthetic isotope time series but has not yet been applied to real-world tracer data. We additionally investigate the sensitivity of new water fractions to discharge, precipitation intensity, and time of year and determine transit time distributions using both ensemble hydrograph separation and power spectrum fitting. We compare results from weekly and 7-hourly sampling, to better understand mixing and storage processes in this extensively studied catchment. We also compare these results to those obtained from chloride time series, to determine whether both passive tracers yield similar inferences about the storage and release of water from the catchment. Through applying 
ensemble hydrograph separation to these unique tracer data sets, we illustrate their usefulness for understanding storage and mixing processes at Plynlimon.

\section{Site description}

The Plynlimon catchments comprise the uppermost headwaters of the river Severn in central Wales and are situated approximately $20 \mathrm{~km}$ inland from the coast. Since the 1960s, Plynlimon has been a focal point for studying the effects of plantation forestry and climate change on the water cycle (Kirby et al., 1991; Durand et al., 1994; Neal et al., 2001, 2003). As part of this research, precipitation and streamflow have been sampled at Plynlimon since the 1980s and analyzed for an unusually wide range of solutes; the resulting publicly available chemical time series are unique worldwide (Neal et al., 2013c, b; Norris et al., 2017).

Plynlimon comprises several catchments that differ in land use and elevation, covering a combined area of $19.25 \mathrm{~km}^{2}$ and ranging in elevation from 319 to $738 \mathrm{~m}$ a.s.l. In this study, we present measurements of stable isotopes and chloride in precipitation as well as in streamflow from three of these catchments, Upper Hafren, Lower Hafren, and Tanllwyth $\left(1.22,3.58\right.$, and $0.92 \mathrm{~km}^{2}$, respectively).

The bedrock at Plynlimon is composed of Lower Paleozoic rocks overlain by acidic soils typically less than $1 \mathrm{~m}$ thick. Paleozoic grits, mudstones, and shales form the parent material of these soils, and soil differentiation depends on drainage. While podzolized soils dominate freely draining areas, blanket peats are found in areas with impeded drainage at higher altitudes (Kirby et al., 1991).

The Upper Hafren catchment consists mainly of seminatural moorland used for sheep grazing. The Lower Hafren and Tanllwyth catchments, by contrast, are covered by coniferous plantation forests (mainly Sitka spruce), which were planted in the 1940s-1960s and have been subjected to phased felling and clear-felling with subsequent replanting over the years (Neal et al., 2001, 2003, 2004a, b). In establishing the forest plantations, soils were plowed and networks of ditches were dug to increase drainage and minimize waterlogging (Neal et al., 2004b). Although large areas of these catchments have since been felled and replanted, these drainage ditches remain, creating flashy hydrograph responses to rainfall (Kirby et al., 1991; Leeks and Marks, 1997; Marks and Rutt, 1997). The climate at Plynlimon is humid and cool, with annual precipitation of approximately $2400 \mathrm{~mm}$, and monthly mean temperatures around $2-3^{\circ} \mathrm{C}$ in winter and $11-13^{\circ} \mathrm{C}$ in summer (Kirby et al., 1991).

\section{Description of the data set}

\subsection{Sample collection and analysis}

A total of 607 precipitation and streamwater samples were collected at weekly intervals between December 2004 and March 2009. Precipitation was sampled as cumulative bulk samples at Carreg Wen, and streamwater was collected as instantaneous grab samples at the Lower Hafren and Tanllwyth sampling points (see Fig. 1). The precipitation samples were collected with a continuously open PVC funnel of $15 \mathrm{~cm}$ diameter with anti-bird protection. This data set is termed the "weekly data" in our analysis.

A further 2113 samples were collected at 7-hourly intervals from July 2007 through March 2009 at Carreg Wen (precipitation) and the Upper Hafren outlet (streamwater). Streamwater sampling was automated using Xian 1000 portable automatic samplers programmed to collect streamwater at 7-hourly intervals into carousels of $24500 \mathrm{~mL}$ bottles, which were picked up from the field site once per week (for details see Neal et al., 2012, 2013a). The entire sampling pathway was flushed with streamwater immediately before the collection of each sample to avoid carryover from the previous sample. The precipitation samples were collected via a continuously open $57.5 \mathrm{~cm}$ funnel with antibird protection, mounted above an autosampler with an enclosed carousel of $24308 \mathrm{~mL}$ bottles, which was also picked up once per week. The resulting data set is termed the "7hourly data" in our analysis.

Both the weekly and 7-hourly sampling of stable water isotopes were embedded in longer-term data collection efforts which have previously been published. Stream chemistry analyses are available weekly from 1983 through 2011 at up to five catchments (Neal et al., 2011, 2013c), and biweekly thereafter (Norris et al., 2017), and are also available at 7-hourly resolution between 2007 and 2009 (Neal et al., 2012, 2013a, b). In addition, hourly meteorological measurements and 15 min stream gauging data from Plynlimon are available starting in the 1970s (CEH, 2019). Thus the isotope measurements presented in this study complement chemical and hydrological data already available to the public.

Rainfall amounts were recorded from a standard, groundlevel tipping bucket rain gauge at the Tanllwyth met site during the weekly sampling (at $350 \mathrm{~m}$ a.s.1.), and at the Carreg Wen automatic weather station during the 7-hourly sampling (at $575 \mathrm{~m}$ a.s.1.). Streamflow was determined from stream gauges at the outlets of the Upper Hafren, Hafren, and Tanllwyth catchments.

Each sample bottle (weekly sampling) or carousel of bottles (7-hourly sampling) was normally processed at the Center for Ecology and Hydrology (CEH), Bangor, UK, the day after it was returned from the field. All samples were filtered $(0.45 \mu \mathrm{m}$ Supor membrane) and then split. One part of the sample was acidified to $1 \% v / v$ with concentrated highpurity $\mathrm{HNO}_{3}$ for analysis of cations and metals, and another 


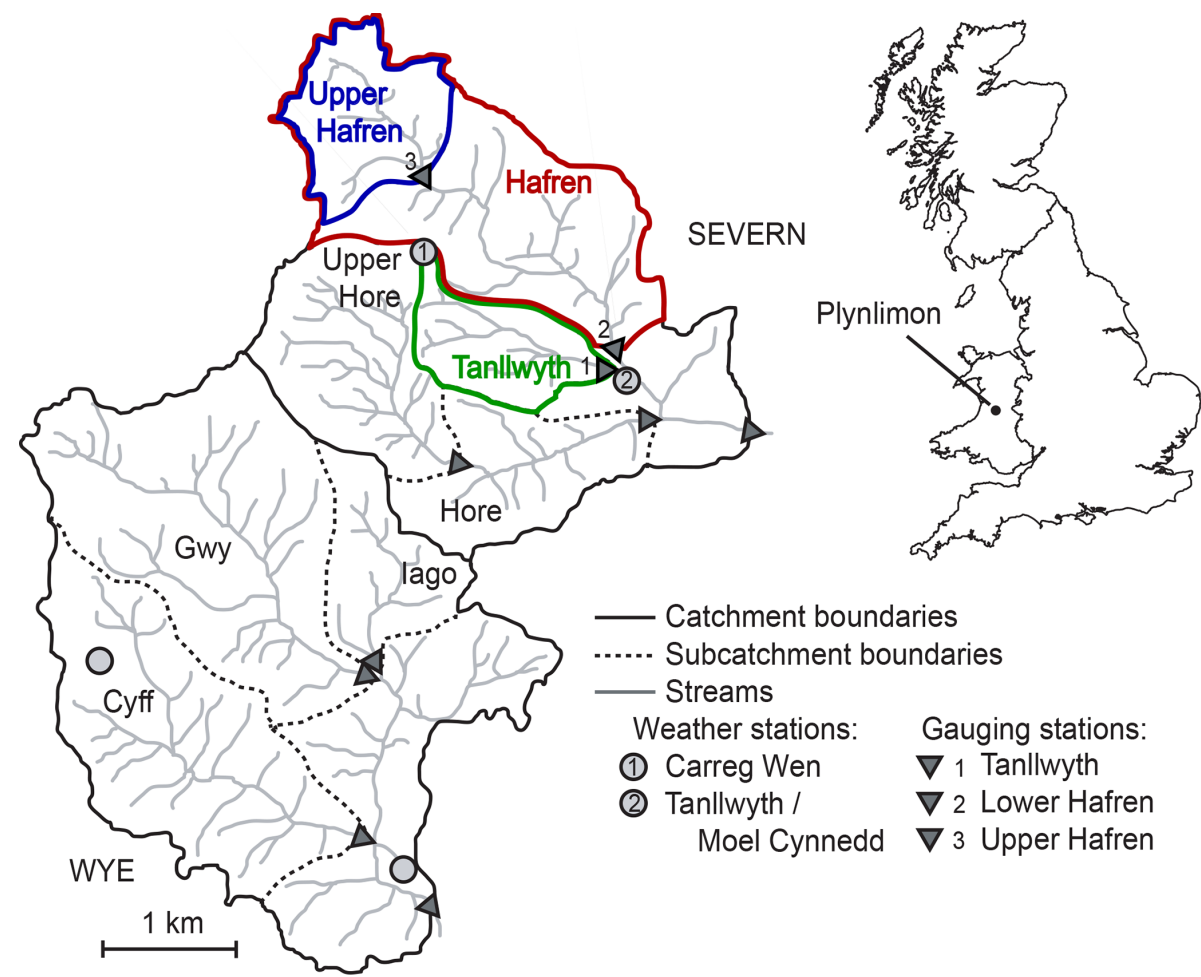

Figure 1. The headwater catchments of the rivers Severn and Wye at Plynlimon, Wales. Stable water isotopes in precipitation were recorded at Carreg Wen (gray circle 1, $575 \mathrm{~m}$ a.s.l.) at weekly and 7-hourly resolution. Weekly streamwater samples of stable water isotopes were collected at Lower Hafren and Tanllwyth (gauging stations indicated by triangles 1 and 2, at 356 and $352 \mathrm{~m}$ a.s.1., respectively), and at 7hourly resolution at Upper Hafren (gauging station denoted by triangle 3, $550 \mathrm{~m}$ a.s.1.). The weather stations at Carreg Wen and Tanllwyth (gray circles 1 and 2) were used to record rates of precipitation at 7-hourly and weekly intervals, respectively.

was bottled without acidification for analysis of anions. A $30 \mathrm{~mL}$ aliquot was also bottled in high-density polyethylene bottles for subsequent isotopic analysis. Usually this aliquot was taken from the un-acidified split, but in some cases it was taken from the acidified split by mistake. The behavior of the acidified and un-acidified samples was broadly similar (see Fig. S2 in the Supplement), but the acidified samples were slightly lighter in deuterium than the un-acidified samples. This offset has been corrected in the data set, and the acidified samples are flagged in the archival data file provided in the Supplement to this paper.

The bottled isotope samples were kept in the dark at or below $5{ }^{\circ} \mathrm{C}$ until they were shipped from CEH to the central laboratory of the Swiss Federal Institute for Forest, Snow and Landscape Research (WSL), Birmensdorf, Switzerland, in 2009. At WSL, all samples were transferred to $2 \mathrm{ml}$ glass vials and closed with $11 \mathrm{~mm}$ snap caps (Infochroma AG, Goldau, Switzerland) with $1 \mathrm{~mm}$ silicone septa. The vials were stored at $-14{ }^{\circ} \mathrm{C}$ for about 1 year, before they were thawed for subsequent analysis.

The samples were analyzed for oxygen- 18 and deuterium isotope ratios at WSL, using a Picarro L1102-i cavity ringdown spectroscopy (CRDS) analyzer equipped with a Picarro V1102-i vaporization module (Picarro, Inc., Sunnyvale, CA,
USA) and a PAL HTC-xt-LEAP-Pic autosampler (CTC Analytics AG, Zwingen, Switzerland). Routine calibrations used three secondary standards (mixed seawater, Fiji artesian water, and Sion drinking water), which in turn were referenced to IAEA VSMOW2, SLAP2, and GISP. All isotope ratios are reported in standard $\delta$ notation relative to the Vienna Standard Mean Ocean Water (VSMOW). Each sample was analyzed twice, separated by at least 100 other samples and standards, and the reported value for each sample is the average of the pair. Any pair that differed by more than $0.20 \%$ in oxygen-18 or $1.0 \%$ in deuterium was re-analyzed (again twice), and whichever of the two pairs was more consistent was averaged for the final reported value. Furthermore, the isotopic composition of some streamwater samples was cross-checked using isotope ratio mass spectrometry (IRMS) and a generally good agreement was found to the CRDS measurements (Fig. S1). More details on the comparison between IRMS and CRDS measurements, and the drift and reproducibility of the measurements, are given in the Supplement.

\subsection{Data set validation and proviso}

The local meteoric water line (LMWL, $\left.\delta^{2} \mathrm{H}=11.8+7.71 \delta^{18} \mathrm{O}\right)$ determined from isotope ratios 

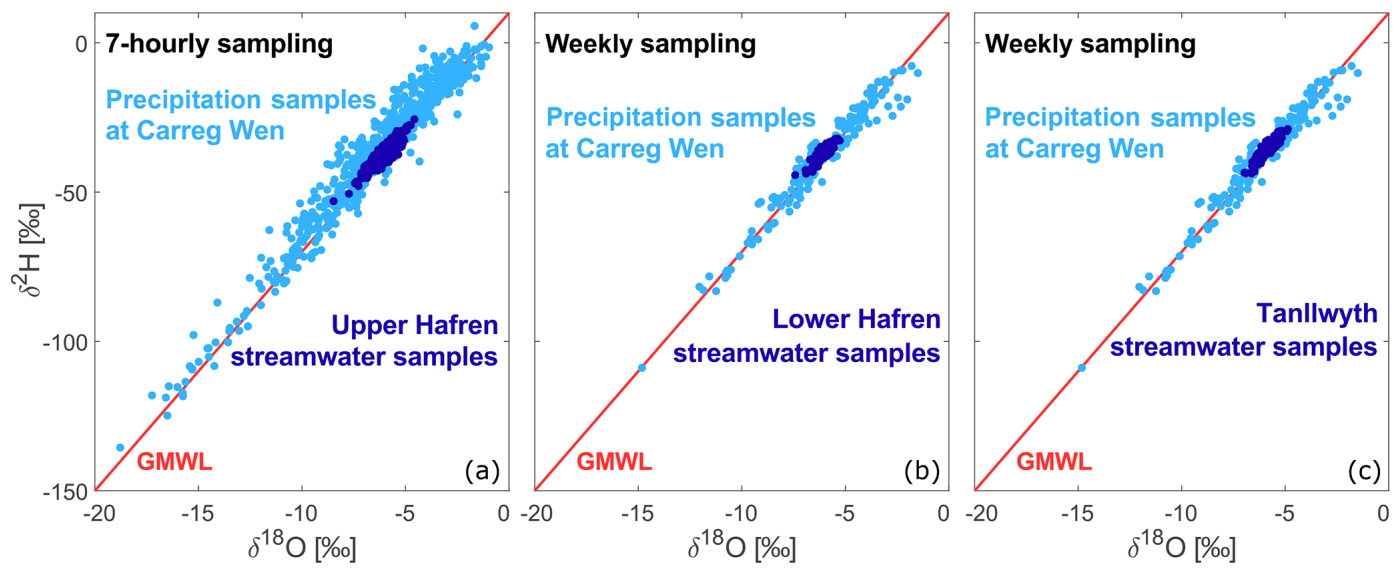

Figure 2. Dual-isotope plots for precipitation (light blue) and streamwater (dark blue) samples from 7-hourly (a) and weekly sampling (bc). Both precipitation and streamwater samples generally fall close to the global meteoric water line (GMWL, red line) and thus show little evidence of evaporative fractionation.

of the 7-hourly precipitation samples fell close to the global meteoric water line (GMWL: $\delta^{2} \mathrm{H}=10+8 \delta^{18} \mathrm{O}$ ). We excluded one 7-hourly streamwater sample from further analysis, since its isotope ratio deviated significantly from the GMWL, suggesting evaporation during storage (see Fig. S3). In addition, some of the weekly samples showed clear evaporation trends and had to be omitted from the data set; they were isotopically heavy in both deuterium and oxygen-18, but followed a line that was much shallower than the meteoric water line, indicating evaporative fractionation. In total around one-eighth of the weekly samples had to be excluded from the data set (22 out of 177 precipitation samples, 25 out of 215 Lower Hafren streamwater samples, and 27 out of 215 Tanllwyth streamwater samples). Most of these sample bottles had visually obvious head space when they were opened for analysis, despite having been completely filled at the time of original sample processing. The dual-isotope plots in Fig. S3 show clear evidence of evaporative fractionation in the excluded samples.

Some of the 7-hourly samples were lost due to sporadic autosampler failures, and all samples collected between December 2007 and the middle of March 2008 were lost following chemical analysis, resulting in a data gap in the 7-hourly isotope time series. As a result, over half of the 7-hourly streamwater samples are missing during the months of December through March. However, the streamwater samples are $98.6 \%$ complete from 18 March through 29 November 2008 (864 samples out of 876 sampling periods) following all quality control checks.

During some sampling intervals, too little rain fell to provide sufficient sample volume, and thus precipitation isotope analyses are missing for some low-volume rainfall events. Conversely, if the rainfall during a $7 \mathrm{~h}$ sampling period exceeded the capacity of the sample bottle $(308 \mathrm{~mL}$, which equals $1.2 \mathrm{~mm}$ of rain), the bottle overflowed. For such precipitation samples, the isotopic ratios of the sample may dif- fer, by an unknown amount, from the volume-weighted averages over the $7 \mathrm{~h}$ interval. Such overflows occurred during approximately $65 \%$ of the $7 \mathrm{~h}$ intervals for which rainfall samples are available. To verify that this did not substantially affect the data, we compared each week's volume-weighted averages of the 7-hourly data to the corresponding weekly bulk precipitation samples and found good agreement. This suggests that isotopic mass balances derived from these data are reliable, even though samples that overflowed comprise the great majority of the total rainfall and within-event variations in precipitation isotopes can be large (Munksgaard et al., 2012; von Freyberg et al., 2017).

The dual-isotope plots in Fig. 2 show that the streamwater and precipitation samples of the final data set fell close to the GMWL, suggesting that they were not greatly affected by evaporative fractionation. Nonetheless, one must consider the possibility that some evaporative fractionation has taken place, particularly in samples collected during the warmer seasons, given that they were stored in the field for up to a week in open bottles within the autosampler. To test for this possibility, we plotted the deuterium excess (Dansgaard, 1964) as a function of season (Fig. 3) and a function of the length of time each sample was stored in the field (Fig. 4). More negative values of deuterium excess indicate greater degrees of evaporative fractionation. Figure 3 shows that the deuterium excess in both the 7-hourly and weekly samples was close to 10 (the GMWL constant, indicated by the reference line in Fig. 3), and was only slightly lower in the summer than the winter. Importantly, the seasonal pattern in deuterium excess in the 7-hourly streamwater samples (which were stored for up to a week in the autosampler in the field) was similar to that in the weekly streamwater samples (which were collected by manual grab sampling and brought directly back to the lab). The similarity in these two deuterium-excess patterns implies that the 7-hourly samples did not undergo significant evaporative fractionation while in storage in the 
autosampler. This inference is corroborated by Fig. 4, which shows that the storage duration in the field had no detectable effect on the deuterium excess in 7-hourly precipitation and streamwater samples, in either the summer or winter seasons.

\subsection{Characteristics of the data set}

Figure 5 shows the 7-hourly and weekly time series of deuterium and oxygen-18 in precipitation and streamwater. The left and right axes are scaled such that fluctuations following the meteoric water line will appear equal, facilitating easier visual comparison. Both isotopes, at both sampling frequencies, show that streamwater isotope variations are very strongly damped compared to precipitation. This directly implies that recent rainfall can only be a minor component of streamflow. Consequently, streamflow must be composed of a mixture of many previous precipitation inputs, and thus the catchment must store and mix waters over a wide range of timescales.

Neither the weekly nor the 7-hourly data exhibit strong seasonal patterns, reflecting the proximity of Plynlimon to the Irish Sea. The weekly precipitation isotope measurements are distinctly less variable than the 7-hourly measurements are, because the weekly samples average over higherfrequency isotopic fluctuations that are captured in the 7hourly samples (Kirchner et al., 2004). The weekly streamflow time series also appears smoother than the 7-hourly time series, but this is largely a visual artifact resulting from the lower density of data points (roughly 200 weekly samples, versus nearly 15007 -hourly samples, in plots of equal width in Fig. 5). Nonetheless, the 7-hourly streamwater sampling does capture several large brief isotopic excursions that are missed by the weekly sampling.

Figure 6 presents a close-up of part of the 7-hourly streamwater isotope time series, revealing rich dynamics in streamwater isotopes that are nearly invisible at the scale of the whole record shown in Fig. 5. The fluctuations in deuterium and oxygen- 18 generally mirror one another, with distinctly larger excursions during high-flow conditions, providing a first indication that higher flows contain larger proportions of recent precipitation, and smaller proportions of older catchment storage. The streamwater isotope fluctuations are much smaller at low flows, but they are not noise. This can be seen by comparing the streamwater isotope time series in Fig. 6 to the green lines, which show a reproducibility test in which a single sample was analyzed 124 times in sequence, revealing the variability that would be expected to arise from analytical noise alone. The variability in the streamwater time series is distinctly larger than this, indicating that it mostly reflects real-world variability in the streamwater isotopes.

The somewhat narrower band of deuterium data, as seen in Fig. 6, presumably reflects the larger measurement noise associated with the oxygen-18 values, or, conversely, the stronger memory effect that arises in deuterium analyses due to the heterogeneous exchange of hydrogen with adsorbed water in the analyzer (Friedman and Irsa, 1952). Both of these hypotheses are consistent with the reproducibility test, in which the replicate oxygen-18 and deuterium measurements had standard deviations of $0.069 \%$ and $0.22 \%$, respectively. Thus, in this test, deuterium was only about 3 times as noisy as oxygen-18, whereas its real-world variability should be 8 times larger than that of oxygen- 18 for samples that follow the meteoric water line. Thus the signal-to-noise ratio in deuterium should be roughly twice as large as in oxygen-18, although deuterium's sample-tosample memory effects were also 3 times larger (see Supplement).

The fluctuation damping in the streamwater isotopes, relative to the much larger fluctuations in precipitation isotopes, can also be visualized through power spectra. As Fig. 7 shows, fluctuations in streamwater isotopes are strongly damped relative to precipitation on all timescales shorter than several years, and the degree of damping systematically grows as frequency increases. There is distinct power-law scaling in both the precipitation and streamwater time series on timescales shorter than roughly 1 month (corresponding to frequencies higher than roughly 10 per year), with steeper scaling in streamwater than precipitation. The spectral slopes of the two isotopes in 7-hourly precipitation are indistinguishable within error $(0.63 \pm 0.03$ and $0.62 \pm 0.02$ for deuterium and oxygen-18, respectively). By contrast, the spectral slope of deuterium in 7-hourly streamwater is distinctly steeper than that of oxygen-18 $(1.57 \pm 0.07$ versus $1.17 \pm 0.02$ ), possibly reflecting greater memory effects during the analysis. The spectral slope of deuterium in weekly streamwater is also slightly steeper than that of oxygen-18 at both Lower Hafren and Tanllwyth, but not by more than the standard error.

\section{Calculation methods}

\subsection{New water fractions and transit time distributions}

The new water fraction $F_{\text {new }}$ uses passive tracers to quantify the average contribution of recent precipitation to streamflow across an ensemble of time steps, using the slope of the simple linear regression (Kirchner, 2019):

$C_{Q_{j}}-C_{Q_{j-1}}=F_{\text {new }}\left(C_{P_{j}}-C_{Q_{j-1}}\right)+\alpha+\varepsilon_{j}$,

where $C_{P_{j}}$ and $C_{Q_{j}}$ represent the tracer concentrations (or isotope values) in precipitation and streamwater, respectively, for a series of sampling times $j ; \alpha$ is the regression intercept, and $\varepsilon_{j}$ is the error term. The uncertainty in $F_{\text {new }}$ can be estimated as the standard error of the regression slope of Eq. (1). This so-called "ensemble hydrograph separation" approach is based on the principle that the larger the fraction of recent precipitation in streamflow, the more tightly correlated their tracer concentrations will be. 

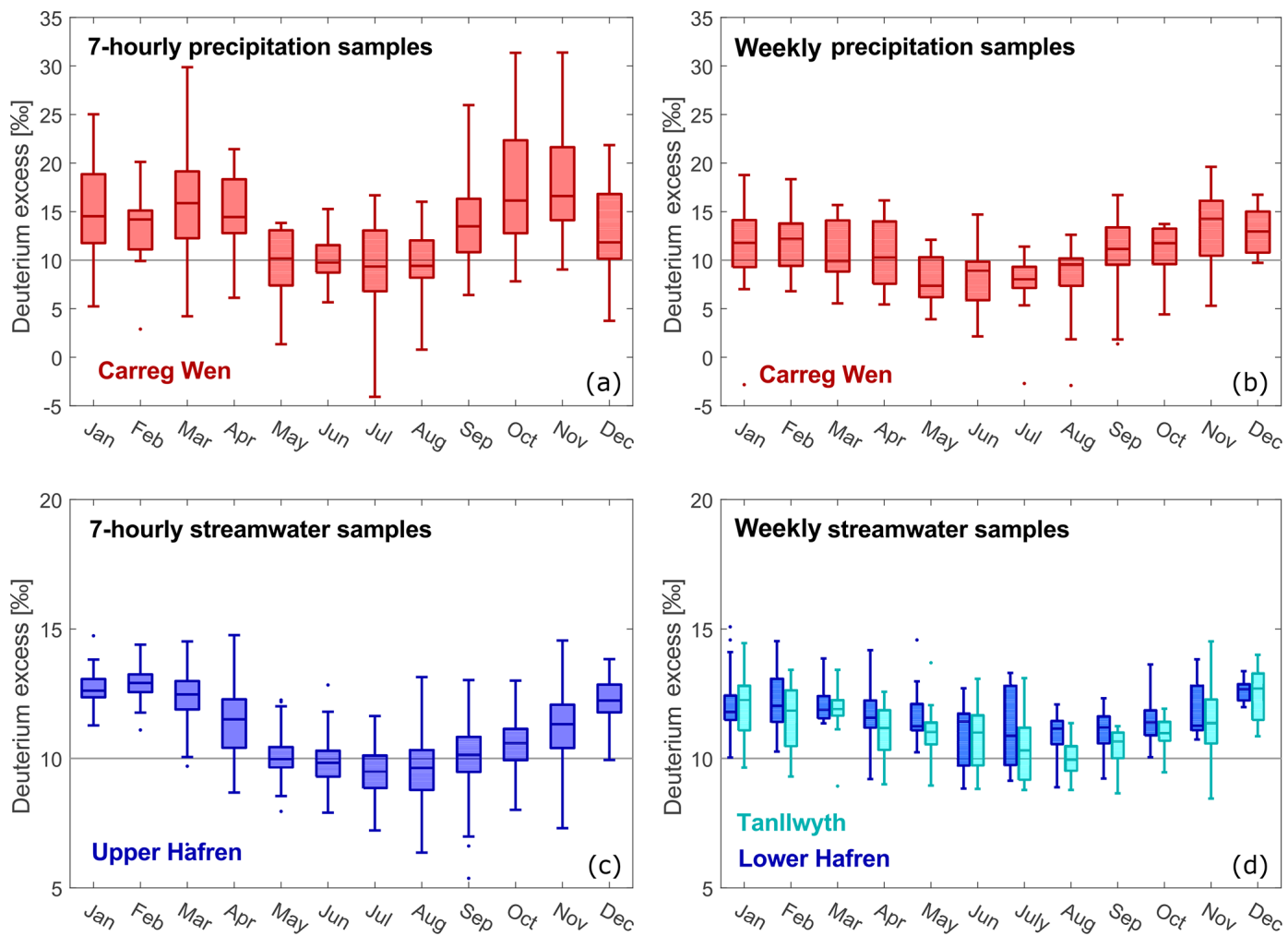

Figure 3. Seasonal variations in deuterium excess for 7-hourly and weekly precipitation samples (a-b) and streamwater samples (c-d). In each boxplot, the center line indicates the median, whereas the box delimits the 25th and 75th percentiles. Whiskers extend twice the interquartile range, or to the maximum and minimum of the data. Outliers beyond the whiskers are indicated by separate points. Axis scales differ between $(\mathbf{a}, \mathbf{b})$ and $(\mathbf{c}, \mathbf{d})$, reflecting the greater variability in precipitation deuterium excess. There are small but distinct seasonal differences in deuterium excess in both precipitation and streamwater. However, the deuterium excess patterns in the 7-hourly streamwater samples mirror those in the weekly grab samples (which were not vulnerable to evaporation in the field), suggesting that these patterns reflect real-world seasonal variations in deuterium excess, and that any evaporative fractionation effects of storage in the 7-hourly samples are small.

New water fractions assess this correlation on the timescale of the sampling frequency and are thus intrinsically tied to it. New water fractions calculated from weekly sampling are "weekly new water fractions", and express the ensemble average contribution to streamflow from precipitation that fell in the previous week. New water fractions calculated from 7-hourly sampling, or "7-hourly new water fractions", will be inherently smaller because they express the contribution to streamflow from precipitation that fell in the previous $7 \mathrm{~h}$ instead of the previous week. As these examples show, new water fractions calculated for time series with different sampling frequencies will differ in both their magnitude and meaning, with smaller new water fractions obtained from higher-frequency sampling. The longer the sampling interval, the more precipitation labeled as "new" will have reached the stream by the time of sampling.

New water fractions can be calculated to represent different aspects of catchment behavior (Kirchner, 2019). Event new water fractions $\left(Q_{\mathrm{p}} F_{\text {new }}\right)$ quantify the proportion of new water found in streamflow for time steps with precipitation, whereas new water fractions for all time steps $\left({ }^{Q} F_{\text {new }}\right)$ scale the event new water fraction by the proportion of days with precipitation to obtain an average value of new water in streamflow, including rainless periods. Similar to these new water fractions of discharge, the new water fraction of precipitation $\left({ }^{P} F_{\text {new }}\right)$ quantifies the fraction of precipitation that becomes streamflow within the given sampling interval (which will generally differ from the fraction of streamflow that is composed of recent precipitation). These new water fractions can be also weighted by volume, giving more weight to sampling times with higher flow, rather than weighting each time interval uniformly; volume-weighted quantities are indicated by an asterisk, i.e., ${ }^{Q_{\mathrm{p}}} F_{\text {new }}^{*},{ }^{Q} F_{\text {new }}^{*}$, and ${ }^{P} F_{\text {new }}^{*}$

Here we calculate new water fractions from both deuterium and oxygen-18 to gain insights into the responses of the Plynlimon catchments to precipitation. We furthermore compare new water fractions for different seasons and discharge regimes to explore how the catchments' behaviors vary under different conditions. To quantify how much precipitation contributes to streamflow over a range of lag times we also determine "backward" and "forward" transit time 

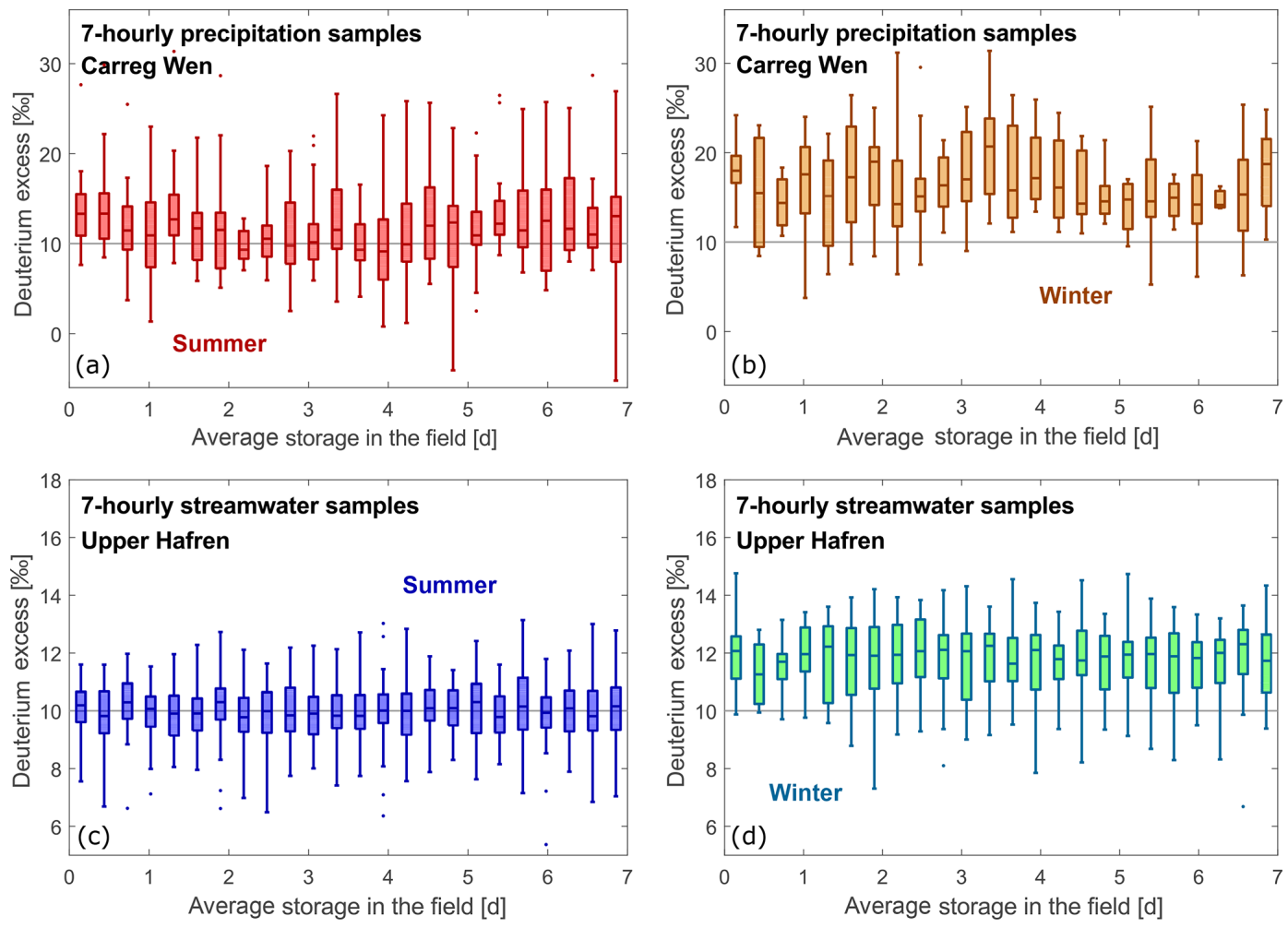

Figure 4. Variations in deuterium excess in 7-hourly samples as a function of the length of time that they were stored inside the field autosamplers. Boxplots are defined as described in Fig. 3. Axis scales differ between (a, b) and (c, d), reflecting the greater variability in precipitation deuterium excess. There is no systematic effect of storage duration on deuterium excess during either summer (May-October, a, c) or winter (November-April, b, d), indicating that any evaporative fractionation during storage was negligible. Deuterium excess in streamwater samples is systematically lower during summer, likely reflecting real-world seasonal variations in deuterium excess (see also Fig. 3).

distributions (which quantify the relative amount of streamflow that originated as rainfall at different prior times, and the relative amount of precipitation that will become streamflow at different future times, respectively), by extending Eq. (1) to a multiple regression that accounts for multiple time lags. For documentation of this method, as well as further details on the ensemble hydrograph separation approach, the conditions under which it holds, and the different types of new water fractions, please see Kirchner (2019).

\subsection{Estimation of transit time distributions from spectra}

The spectral damping shown in Fig. 7 can be used to estimate equivalent transit time distributions to those estimated by ensemble hydrograph separation. Our approach is based on the convolution theorem of linear systems analysis, which implies that the power spectrum of the streamwater isotope time series should equal the power spectrum of the precipitation isotope time series, multiplied by the power spectrum of the transit time distribution. We assume that the transit time distribution is approximated by the gamma distribution, $p(\tau)=\frac{\tau^{k-1} e^{-\tau / \theta}}{\theta^{k} \Gamma(k)}$,

where $\tau$ is the transit time, $\theta$ and $k$ are scale and shape parameters, and $\Gamma(k)$ is the gamma function. The mean transit time can be calculated as $\bar{\tau}=k \theta$, but it will be very sensitive to the tail of the distribution, and thus difficult to constrain from relatively short, high-frequency tracer time series. To estimate the parameters $\theta$ and $k$, we multiplied the power spectrum $S_{P}(\omega)$ of the precipitation isotope time series by the power spectrum of the gamma distribution, to yield an estimate of the power spectrum $S_{Q}(\omega)$ of the streamwater isotope time series:

$S_{Q}(\omega)=S_{P}(\omega)\left[1+(\omega \theta)^{2}\right]^{-k}$,

where $\omega=2 \pi f$ is the angular frequency. We estimated the parameters $\theta$ and $k$ in Eq. (3) by minimizing the sum of squared deviations between the logarithm of the predicted spectrum $S_{Q}(\omega)$ and the logarithm of the measured tracer spectrum in streamwater, using the analytic GaussNewton algorithm as implemented in JMP v. 14.3 (SAS Institute, Cary, NC, USA). Weighted transit time distributions 

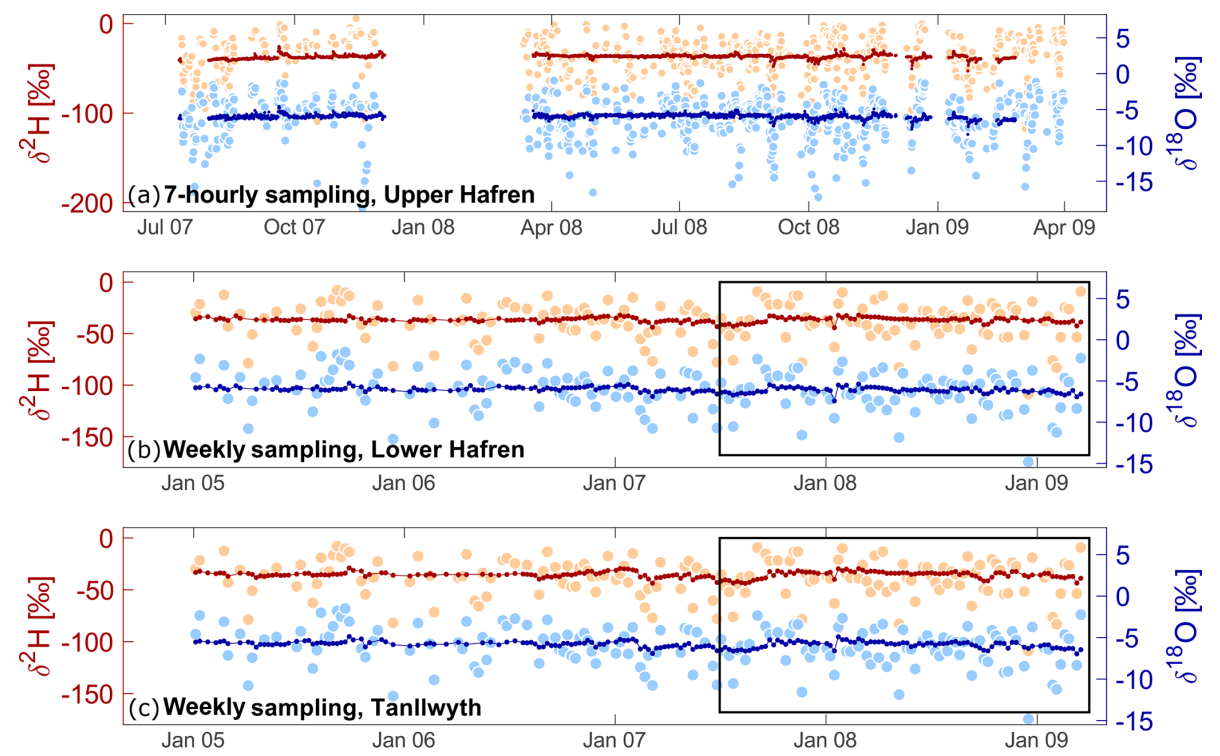

Figure 5. Time series of stable water isotopes measured at 7-hourly resolution (a) and weekly resolution (b-c) in precipitation (lighter colors) and streamwater (darker colors). All precipitation samples were collected at Carreg Wen, and 7-hourly streamwater samples were collected at the Upper Hafren catchment outlet, whereas weekly streamwater samples were collected at the Lower Hafren and Tanllwyth catchment outlets. The deuterium axis (left) is compressed by a factor of 8 relative to the oxygen-18 axis (right). Consequently, fluctuations along the meteoric water line would appear equally large for both isotopes. The black rectangles shown in the weekly plots indicate the period of the 7-hourly sampling.

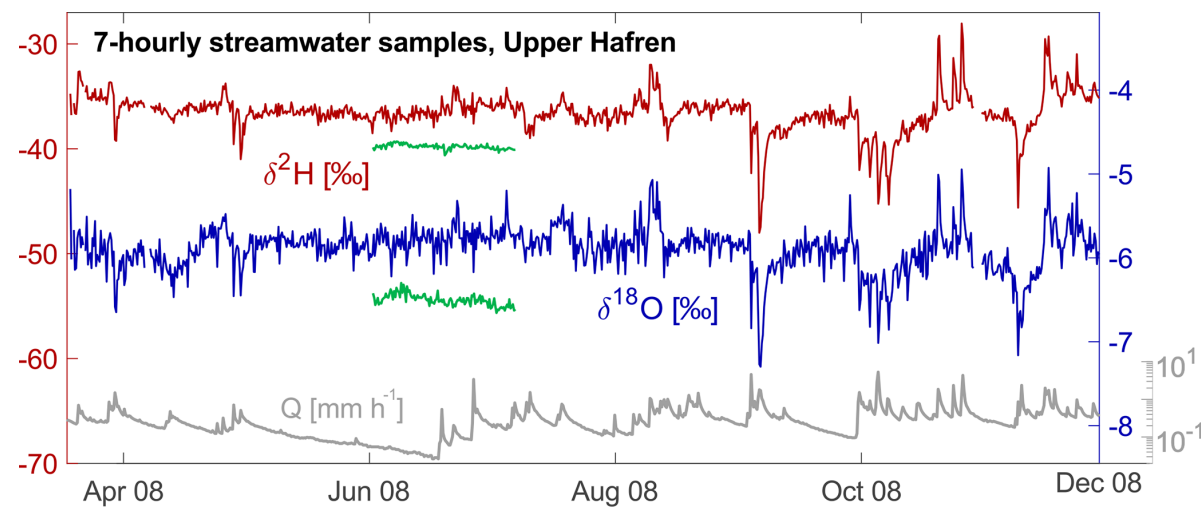

Figure 6. A close-up of 8 months of nearly complete streamwater samples from 7-hourly sampling. Deuterium (left axis) is shown in red, oxygen-18 (right axis) in blue, and discharge is shown in gray. The fluctuations of the replicate QC standards from the reproducibility test (green) illustrate the magnitude of the variability between samples due to analytical noise.

can also be estimated from Eq. (3), using a precipitationweighted spectrum of the precipitation tracer time series, and a discharge-weighted spectrum of the streamwater tracer time series.

\subsection{Comparison to chloride data}

Many studies of catchment transit times and rainfall-runoff processes are based on stable water isotopes. Until recently, however, stable isotope measurements were expensive and therefore relatively rare. Instead, chloride has been widely used as a passive tracer, under the assumption that it is trans- ported conservatively through the catchment. However, dry deposition of aerosols can account for a substantial share of the total chloride input, particularly at catchments like Plynlimon that are close to the coastline (Neal and Rosier, 1990; Neal and Kirchner, 2000). At Plynlimon, dry deposition accounts for about $10 \%-20 \%$ of total chloride inputs from the atmosphere (Durand et al., 1994; Wilkinson et al., 1997). Dry deposition greatly increases the variability of the precipitation concentrations, but it probably has a small effect on calculated fluxes, because samples dominated by dry deposition are usually associated with small volumes of water. However, the ensemble hydrograph separation approach uses 

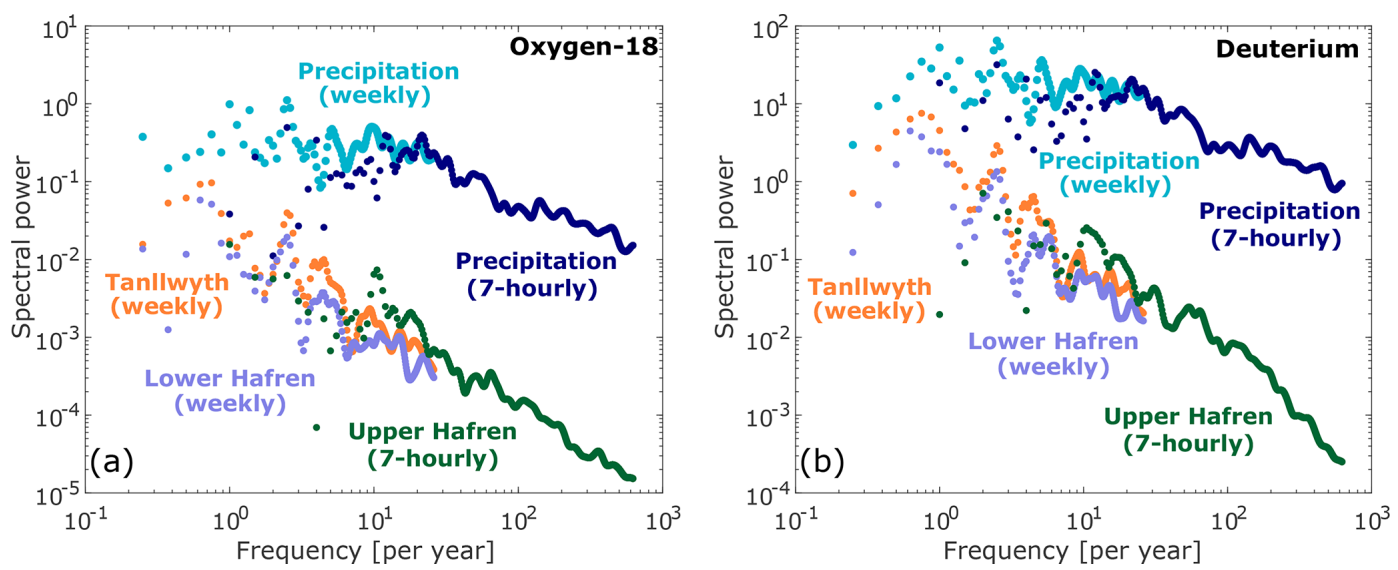

Figure 7. Power spectra of fluctuations in oxygen-18 (a) and deuterium (b) in precipitation and streamwater, calculated using the weighted wavelet and alias filtering methods of Kirchner (2005) and Kirchner and Neal (2013). Weekly and 7-hourly streamwater spectra are not strictly comparable because they are measured in different streams, whereas weekly and 7-hourly precipitation spectra were calculated from samples collected at the same location (although during partly non-overlapping time periods).

concentration data, and specifically the damping observed between catchment input and output concentrations, to determine fractions of recent precipitation in streamflow. It is thus highly sensitive to the variability of the input signal. Noise introduced into the input signal through dry deposition can bias the results towards smaller new water fractions, because the higher variability in the input signal incorrectly implies a stronger damping between the input and output signal. To minimize this bias, we excluded all 7-hourly precipitation chloride samples that were potentially influenced by dry deposition according to several soft and hard criteria, e.g., very high concentrations in small sample volumes, or samples immediately following extended intervals without precipitation. The details of this filtering procedure are explained in the supplements.

We did not apply a similar filtering procedure to the weekly precipitation samples, because we expected them to be much less affected by dry deposition. The 7-hourly samples were particularly vulnerable to dry deposition because they were collected using a large funnel, which required only a very small input of liquid precipitation to make a measurable sample volume (e.g., only $0.4 \mathrm{~mm}$ of precipitation yielded $100 \mathrm{~mL}$ of sample). By contrast, the funnel used for the weekly sampling was substantially smaller, so more wet deposition was required to make a measurable sample, thus providing greater dilution of any dry deposition. Nonetheless, we removed chloride samples with concentrations more than 3 standard deviations above or below the mean, as potential outliers, from the weekly precipitation and streamwater time series (as well as from the 7-hourly streamwater time series).

\subsection{Aggregation of sampling intervals}

To investigate the scaling of new water fractions with the length of the sampling interval, and to allow a comparison between the three catchments, we combined sequential sets of 7-hourly samples to synthesize longer sampling intervals. In case of the instantaneous streamwater samples, only the grab sample collected at the end of the aggregated sampling interval was considered, and all other samples in between were disregarded. Precipitation samples, on the other hand, are cumulative samples. Therefore, all individual samples collected during an aggregated sampling interval were averaged together, weighted by their respective precipitation rates.

The longer the aggregated sampling interval, the greater the number of possible combinations of samples. To exclude the possibility that an arbitrary choice of sample combinations would affect the results, we calculated new water fractions with all possible sample combinations, and averaged the resulting quantities.

\section{Results and discussion}

\subsection{New water fractions}

We calculated new water fractions using deuterium, oxygen18 , and chloride collected at 7-hourly and weekly intervals (Table 1). The 7-hourly new water fractions (calculated from 7-hourly isotope data) show that on average, slightly less than $3 \%$ of streamflow was made up of precipitation that fell within the last $7 \mathrm{~h}$. Weekly new water fractions (calculated from weekly isotope data) show that on average $13 \%-15 \%$ of streamflow consisted of precipitation that fell within the last week. (For both sampling frequencies, these are volumeweighted new water fractions for all time steps, $Q_{F_{\text {new }}}^{*}$, and 
Table 1. New water fractions ( \pm standard errors) calculated from 7-hourly and weekly measurements of deuterium, oxygen-18, and chloride (chloride time series at 7-hourly resolution were corrected for dry deposition before the calculation of new water fractions). From top to bottom: new water fractions calculated using all time steps, event new water fractions calculated from time steps with precipitation, and new water fractions of precipitation, each calculated with and without volume-weighting. New water fractions cannot be directly compared between the two sampling frequencies.

\begin{tabular}{|c|c|c|c|}
\hline & $\begin{array}{r}\text { 7-hourly sampling } \\
\text { at Upper Hafren } \\
2007-2009\end{array}$ & $\begin{array}{r}\text { Weekly sampling } \\
\text { at Lower Hafren } \\
2005-2009\end{array}$ & $\begin{array}{r}\text { Weekly sampling } \\
\text { at Tanllwyth } \\
2005-2009\end{array}$ \\
\hline \multicolumn{4}{|c|}{ New water fractions for all time steps ${ }^{\mathrm{a}}, Q_{F_{\text {new }}}(\%)$} \\
\hline Deuterium & $0.88 \pm 0.11$ & $4.93 \pm 0.72$ & $5.58 \pm 0.71$ \\
\hline Oxygen-18 & $0.90 \pm 0.15$ & $4.43 \pm 0.87$ & $5.69 \pm 0.82$ \\
\hline Chloride & $0.54 \pm 0.11$ & $11.07 \pm 2.12$ & $11.93 \pm 2.02$ \\
\hline \multicolumn{4}{|c|}{ Volume-weighted new water fractions for all time steps ${ }^{\mathrm{b}}, Q_{F_{\text {new }}^{*}}^{*}(\%)$} \\
\hline Deuterium & $2.95 \pm 0.41$ & $13.19 \pm 1.88$ & $14.61 \pm 1.81$ \\
\hline Oxygen-18 & $2.90 \pm 0.49$ & $13.26 \pm 2.23$ & $15.27 \pm 2.09$ \\
\hline Chloride & $1.99 \pm 0.41$ & $27.40 \pm 4.64$ & $24.25 \pm 5.54$ \\
\hline \multicolumn{4}{|c|}{ Event new water fractions ${ }^{\mathrm{c}}, Q_{\mathrm{p}} F_{\text {new }}(\%)$} \\
\hline Deuterium & $2.42 \pm 0.31$ & $7.36 \pm 1.08$ & $8.33 \pm 1.07$ \\
\hline Oxygen-18 & $2.47 \pm 0.40$ & $6.61 \pm 1.30$ & $8.50 \pm 1.23$ \\
\hline Chloride & $1.49 \pm 0.31$ & $16.54 \pm 3.16$ & $17.82 \pm 3.01$ \\
\hline \multicolumn{4}{|c|}{ Volume-weighted event new water fractions ${ }^{\mathrm{d}}, Q_{\mathrm{p}} F_{\text {new }}^{*}(\%)$} \\
\hline Deuterium & $5.02 \pm 0.70$ & $14.57 \pm 2.08$ & $15.90 \pm 1.97$ \\
\hline Oxygen-18 & $4.93 \pm 0.83$ & $14.63 \pm 2.46$ & $16.62 \pm 2.28$ \\
\hline Chloride & $3.39 \pm 0.70$ & $30.25 \pm 5.13$ & $26.40 \pm 6.03$ \\
\hline \multicolumn{4}{|c|}{ New water fractions of precipitation ${ }^{\mathrm{e}},{ }^{P} F_{\text {new }}(\%)$} \\
\hline Deuterium & $1.41 \pm 0.18$ & $5.93 \pm 0.87$ & $7.33 \pm 0.94$ \\
\hline Oxygen-18 & $1.44 \pm 0.23$ & $5.32 \pm 1.05$ & $7.48 \pm 1.08$ \\
\hline Chloride & $0.87 \pm 0.18$ & $13.32 \pm 2.54$ & $15.68 \pm 2.65$ \\
\hline \multicolumn{4}{|c|}{ Volume-weighted new water fractions of precipitation ${ }^{\mathrm{f}},{ }^{P} F_{\text {new }}^{*}(\%)$} \\
\hline Deuterium & $2.86 \pm 0.40$ & $11.16 \pm 1.59$ & $13.30 \pm 1.64$ \\
\hline Oxygen-18 & $2.81 \pm 0.47$ & $11.21 \pm 1.88$ & $13.91 \pm 1.90$ \\
\hline Chloride & $1.93 \pm 0.40$ & $23.17 \pm 3.93$ & $22.08 \pm 5.04$ \\
\hline
\end{tabular}

thus include periods where no precipitation fell.) These results illustrate that the numerical values of new water fractions, and also their meaning, are intrinsically tied to the sampling frequency: "new" water is water that fell as rain during the last sampling interval, whether that interval is $7 \mathrm{~h}$ or $7 \mathrm{~d}$. The small 7-hourly new water fraction is not surprising, as $7 \mathrm{~h}$ is a relatively short time for any raindrop to reach the catchment outlet, unless it lands directly in the channel itself. Instead, most streamflow is dominated by older water that originated from previous precipitation events and has been stored within the catchment for months or longer. Unsurprisingly, across all sites and sampling frequencies, volumeweighted new water fractions were larger than unweighted new water fractions, because volume-weighting gives more emphasis to higher flows which typically contain larger proportions of recent precipitation.

In contrast to the pronounced differences between the 7 hourly and weekly new water fractions, the weekly sampling at Lower Hafren and Tanllwyth yielded broadly similar new water fractions, with slightly higher values at Tanllwyth than at Lower Hafren. The higher new water fractions in the Tanllwyth catchment can be plausibly attributed to its higher prevalence of low-permeability gley soils (Neal et al., 2004b), which would tend to promote faster near-surface flows.

Event new water fractions $\left(Q_{\mathrm{p}} F_{\text {new }}\right)$ are calculated only over time steps with precipitation and thus are always larger than new water fractions averaged over all time steps, including rainless periods $\left({ }^{Q} F_{\text {new }}\right)$. In the weekly data, this differ- 
ence was relatively small, because almost all time steps had precipitation (roughly $70 \%$ of weeks had precipitation rates above the threshold, here set to $\bar{P} \approx 0.1 \mathrm{~mm} \mathrm{~h}^{-1}$ for both weekly and 7-hourly sampling). By contrast, the 7-hourly event new water fraction $\left(Q_{\mathrm{p}} F_{\text {new }}\right)$ was roughly $1.5-3$ times higher than the new water fraction for all time steps $\left(Q_{F_{\text {new }}}\right)$, because most $7 \mathrm{~h}$ intervals were rainless (and therefore could not contribute any new water, because new water is defined as precipitation that fell within the current time step). Only about $35 \%$ of 7-hourly periods had precipitation rates higher than the threshold; roughly $50 \%$ had no precipitation at all, and another $15 \%$ had some precipitation but less than the threshold. New water fractions of precipitation $\left({ }^{P} F_{\text {new }}\right.$, the fractions of precipitation becoming streamflow in the same time step) were somewhat smaller than event new water fractions $\left(Q_{\mathrm{p}} F_{\text {new }}\right.$, the fractions of streamflow originating as precipitation in the same time step). This was because during most storms the rainfall rate will be higher than the streamflow rate, so the ratio between same-time-step streamflow and the total rainfall rate $\left({ }^{P} F_{\text {new }}\right)$ will necessarily be smaller than the ratio between same-time-step streamflow and the total streamflow rate $\left(Q_{\mathrm{p}} F_{\text {new }}\right)$ (Kirchner, 2019). This contrast in water fluxes was less pronounced at the weekly timescale, so the contrast between the weekly new water fractions of precipitation and discharge was also less pronounced. The volume-weighted new water fractions of precipitation and discharge $\left({ }^{P} F_{\text {new }}^{*}\right.$ and $\left.Q_{F_{\text {new }}^{*}}\right)$ are related by the ratio of total discharge to total precipitation; in Plynlimon's very humid climate, this ratio is close to 1 and thus these two new water fractions were nearly equivalent.

The previous paragraphs, along with Table 1, demonstrate that substantially different values can be obtained, depending on which type of new water fraction is calculated. Whether event new water fractions, new water fractions for all time steps, or new water fractions of precipitation should be calculated will depend on the scientific question, because they provide somewhat different types of information. For this reason, it may be beneficial to compute several different variants, as we have done here, to obtain a more holistic picture of catchment processes. In general, one can expect that volume-weighted new water fractions will give more reproducible results than unweighted new water fractions, because they will give less weight to low-volume samples that may have anomalous tracer values.

New water fractions determined from deuterium and oxygen-18 agreed within one pooled standard error. 7-hourly new water fractions determined from the dry-depositionfiltered 7-hourly chloride time series were systematically smaller than those calculated from stable isotopes, but nonetheless in a similar range. This result suggests that the dry deposition filtering performed on the 7-hourly chloride data worked reasonably well. Conversely, new water fractions determined from weekly chloride samples (which were not corrected for effects of dry deposition) were significantly larger than those obtained from stable water isotopes.

\subsection{Effect of the precipitation threshold}

We calculated new water fractions assuming different precipitation thresholds, below which samples were considered unreliable and excluded from the analysis. Volume-weighted event new water fractions $\left(Q_{\mathrm{p}} F_{\text {new }}^{*}\right)$ increased with increasing precipitation thresholds in our analysis (Fig. 8a, b), as time steps with higher volumes were inherently given increasing weight. Conversely, volume-weighted new water fractions determined for all time steps $\left(Q_{F_{\text {new }}}^{*}\right)$ were affected less by the precipitation threshold, due to the scaling factor accounting for the increasing fraction of days without precipitation above the threshold (Fig. 8c, d).

The change in new water fractions with increasing precipitation thresholds was very similar between the two stable water isotopes (see Fig. 8). In contrast, 7-hourly new water fractions calculated directly from the 7-hourly chloride time series (without filtering for dry deposition effects) were substantially smaller. This was likely due to the higher variability in precipitation concentrations due to dry deposition effects, leading to a stronger apparent damping of chloride concentrations than stable water isotopes between precipitation and streamwater. After precipitation chloride values that were potentially affected by dry deposition were removed from the analysis (6.6\% of samples, equaling 50 out of 751 data points), 7-hourly new water fractions determined from chloride agreed within error with those determined from the stable water isotopes, as long as the precipitation threshold was higher than the mean precipitation rate (Fig. 8).

For the weekly chloride data, we expected the effect of dry deposition to be less important (and more difficult to assess), so we only performed a general outlier removal. The resulting chloride time series yielded substantially higher weekly new water fractions than those obtained from the stable water isotopes. This discrepancy was largest for small precipitation thresholds, but substantial throughout. This effect cannot be explained by the dry deposition of chloride alone, because we would expect this to increase the variability in the precipitation time series and thus reduce the weekly new water fraction (as we saw in the 7-hourly samples). Instead, the damping from precipitation to streamflow seems to be weaker for chloride than the stable water isotopes in the weekly data set. This was previously discussed by Neal and Rosier (1990), who linked a lower degree of damping for chloride to evaporative concentration of chloride in the catchment, resulting in a more heterogeneous distribution of chloride. The sensitivity of chloride to evapoconcentration and its substantial effect of the damping of chloride signals were also shown by (Hrachowitz et al., 2015).

Recommending an ideal precipitation threshold is not trivial and likely depends on the frequency and intensity of rain events, as well as the sampling frequency. If the precipitation threshold is set too low, potentially unreliable data points from small-volume samples will be included in the analysis. Conversely, if the threshold is set too high, many sam- 

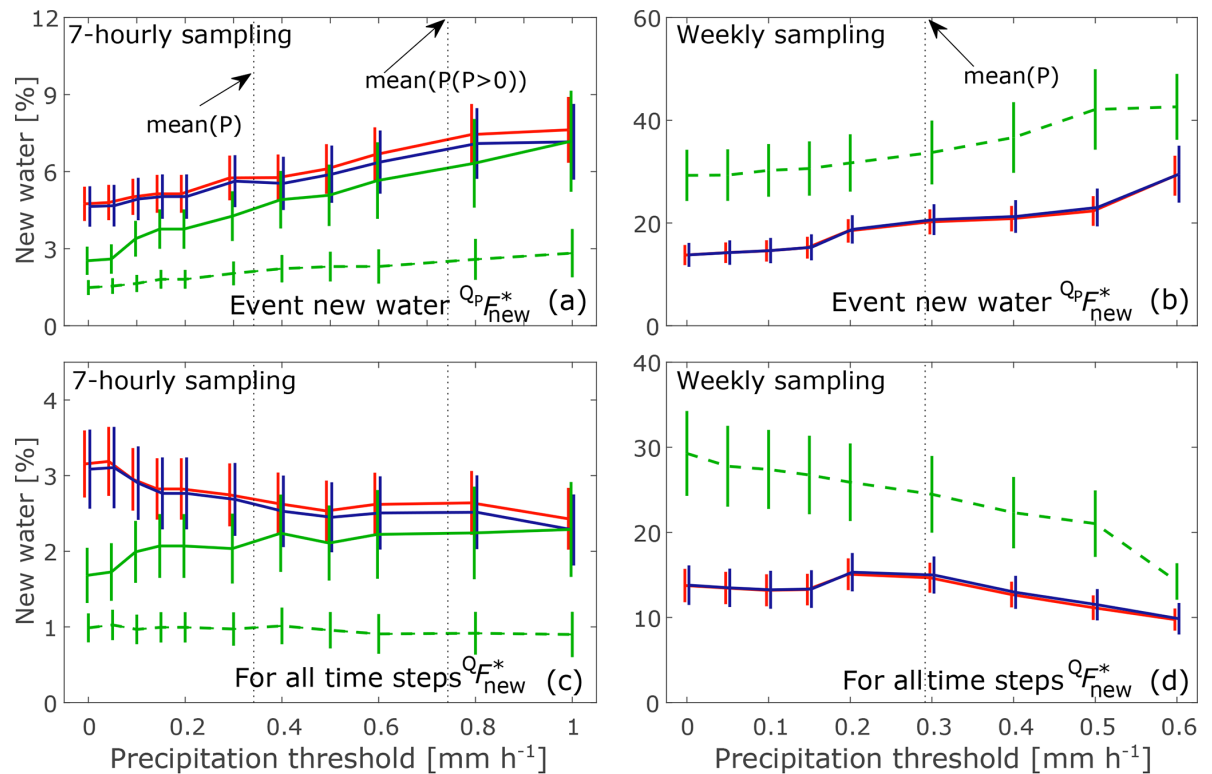

$\begin{array}{ll}- \text { Deuterium } & \text { Chloride (dry dep. corrected) } \\ - \text { Oxygen-18 } & --- \text { Chloride }\end{array}$

Figure 8. Effects of different precipitation thresholds on volume-weighted new water fractions for 7-hourly sampling at Upper Hafren (a, c) and weekly sampling at Lower Hafren (b, d). Error bars indicate 1 standard error. Panels (a)-(b) show volume-weighted event new water fractions $\left(Q_{\mathrm{p}} F_{\text {new }}^{*}\right)$, which consider only time steps with precipitation. Higher precipitation thresholds lead to higher new water fractions in these panels, because time steps with low precipitation rates are usually associated with lower discharges. As these are excluded, fewer and fewer low-flow time steps are considered, increasing the relative importance of time steps with high discharge, which also tend to have higher new water fractions. Conversely, the precipitation threshold has less effect on volume-weighted new water fractions for all time steps $\left(Q_{F_{\text {new }}}^{*}, \mathbf{c}-\mathbf{d}\right)$, because these include a factor that accounts for the fraction of days without precipitation. Precipitation thresholds have been slightly jittered for better visibility of the different tracers.

ples will be excluded from the analysis, increasing the uncertainty in the calculated new water fractions due to the reduced sample size. In this study, a precipitation threshold of $0.1 \mathrm{~mm} \mathrm{~h}^{-1}$ for both 7-hourly and weekly data gave, in our view, reasonable results. If different systems are compared, we recommend choosing a precipitation threshold that will exclude similar fractions of precipitation volumes and isotope samples, In our study, the threshold of $0.1 \mathrm{~mm} \mathrm{~h}^{-1}$ led to an exclusion of approximately $2 \%$ and $5 \%$ of the total precipitation volumes, and of approximately $16 \%$ and $21 \%$ of the isotope samples, for 7-hourly and weekly sampling, respectively. This threshold value was used in all analyses presented here, unless explicitly stated otherwise.

\subsection{Comparison of results from aggregated 7-hourly samples and weekly samples}

To test how different sampling frequencies could affect estimates of new water fractions, we aggregated the 7-hourly data to synthesize longer sampling intervals. As the length of the sampling interval changes, so does both the magnitude, and the meaning, of the new water fraction. "New" water is defined as streamflow that fell as precipitation within the last sampling interval. Thus it is not surprising, for example, that the fraction of streamflow that fell as precipitation within the last week (the weekly new water fraction) will be larger than the fraction of streamflow that fell as precipitation within the last $7 \mathrm{~h}$ (the 7-hourly new water fraction). As expected, the new water fraction increased with the length of the (synthetic) sampling intervals shown in Fig. 9. The curves shown here increase rather steeply over the first day, and more gradually over longer sampling intervals. The new water fraction obtained from synthetic weekly sampling was around 3 times higher than that from 7-hourly sampling in case of the stable isotopes. One might have expected an increase by a factor of 24 between sampling interval lengths of $7 \mathrm{~h}$ to 1 week (because $24 \times 7 \mathrm{~h}=1$ week). The observed increase is smaller for two reasons. The first reason is that, as the sampling interval increases, the average time lag also increases between any individual precipitation event and the moment that the stream is sampled. As this lag time increases, so does the chance that recent precipitation will have already passed the sampling point by the time that the sample is collected. The second reason arises from how stochastic rainfall events are aggregated as the sampling interval increases. In any given week (for example), there may be several $7 \mathrm{~h}$ periods when 

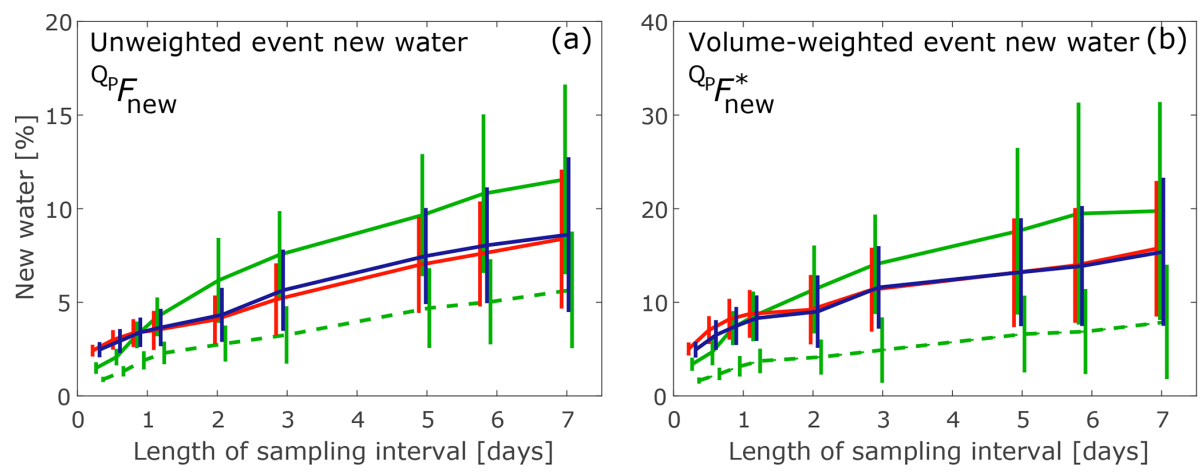

\begin{tabular}{ll|}
- Deuterium & Chloride (dry dep. corrected) \\
- Oxygen-18 & --- Chloride
\end{tabular}

Figure 9. Effects of aggregating 7-hourly data to longer sampling intervals for deuterium (red), oxygen-18 (blue), and chloride (green) with and without correction for dry deposition effects. Error bars indicate 1 standard error. The new water fractions determined from the stable water isotopes are nearly identical, whether unweighted (a) or volume-weighted (b). Sampling interval lengths have been slightly jittered for better visibility of the different tracers.

rain falls, but many others when it does not. Event new water fractions of the 7-hourly data would count only the $7 \mathrm{~h}$ periods with rain and would ignore the rest. The event new water fraction for the entire week will include these rainless periods (but the week will still be classified as an "event" because it includes some periods of rainfall). Thus the event new water fraction at the weekly timescale will be smaller than if it consisted entirely of rainy intervals. (Of course, even $7 \mathrm{~h}$ events may include rainless periods, so although this thought experiment explains how new water fractions scale with the sampling interval, it does not argue for any particular interval being the "correct" one.)

In Fig. 9, similar to Table 1 and Fig. 8, the new water fractions determined from deuterium and oxygen- 18 were nearly identical, whereas those determined from chloride deviated somewhat. If dry deposition was not accounted for, the new water fraction was substantially smaller than the new water fraction determined from stable isotopes, particularly for sampling intervals of $1 \mathrm{~d}$ or less. If the effect of dry deposition was filtered out, new water fractions determined from chloride were within 1 standard error of those determined from stable water isotopes, except for the shortest sampling interval. This pattern was consistent for both unweighted and volume-weighted new water fractions. The analysis thus showed that chloride may be a suitable passive tracer, if potential effects of dry deposition are removed. The suitability of chloride as a passive tracer consequently depends on how well dry deposition effects can be identified and eliminated. However, it is important to note that the filtering approach for dry deposition employed here was not empirically validated and was not based on physical effects like wind speed or direction. Furthermore, the removal of dry-deposition-affected samples leads to reduced mass recovery. In the ensemble hydrograph separation approach this has only a small effect, because only the correlation between the input and output signal is assessed. In other approaches, however, a correct mass balance is essential. Therefore, we argue that the stable water isotope data provide a better and more reliable data set to quantify catchment characteristics, mixing, and storage processes.

We can directly compare the new water fractions of all three sites, if we put them on a consistent time base. We aggregated the 7-hourly samples at Upper Hafren to mimic the samples that would have been obtained through weekly sampling. We then took a subset of the weekly data at Lower Hafren and Tanllwyth, coinciding with the period of the $7 \mathrm{~h}$ sampling at Upper Hafren (and excluding the long data gap in the $7 \mathrm{~h}$ samples between December 2007 and March 2008). With all three catchments on this consistent time base, their unweighted weekly new water fractions were broadly similar, with a small increase in weekly new water fractions from Lower Hafren to Tanllwyth to Upper Hafren (Table 2). Their volume-weighted weekly new water fractions, however, were systematically larger at Lower Hafren and Tanllwyth than at Upper Hafren, which is consistent with faster routing of new water, particularly at high flows, due to the drainage ditches in the Lower Hafren and Tanllwyth plantation forests.

\subsection{Variation in new water fractions with hydraulic regime and season}

We calculated new water fractions from the oxygen-18 time series, subsampled to capture different percentiles of the discharge and precipitation distributions (Fig. 10). The new water fraction increased with discharge and precipitation, indicating (unsurprisingly) that recent precipitation contributed more to streamflow during large events. This was likely due to greater saturation of soils during intense rain events, resulting in a greater dominance of shallow flowpaths and 

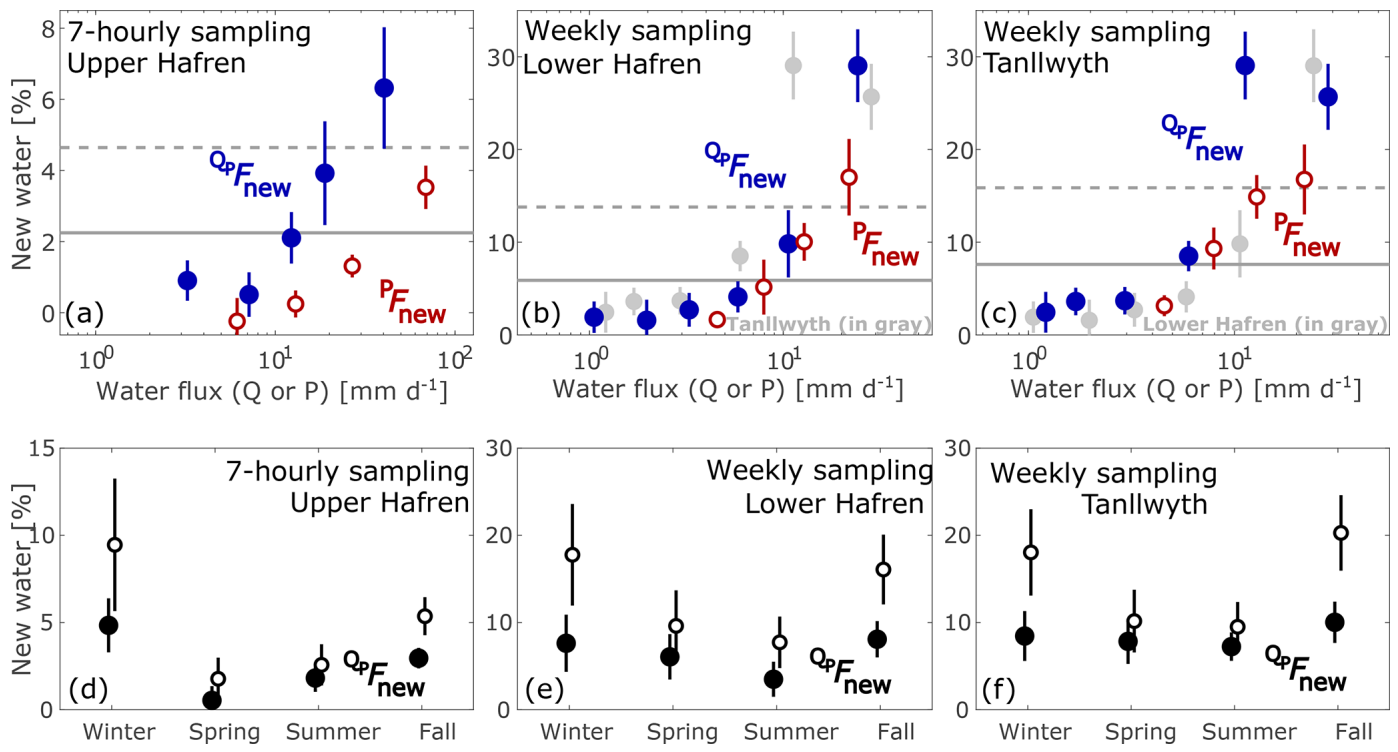

Figure 10. Event new water fractions $\left(Q_{\mathrm{p}} F_{\text {new }}\right)$ and new water fractions of precipitation $\left({ }^{P} F_{\text {new }}\right)$ for different discharge rates, precipitation rates, and seasons, calculated from time series of oxygen-18. Error bars indicate 1 standard error. In (a)-(c), solid circles indicate event new water fractions, plotted as functions of discharge rates, and open circles indicate new water fractions of precipitation, plotted as functions of precipitation rates. Gray markers in the background of (b) show event new water fractions from (c), and vice versa, to facilitate comparison between Lower Hafren and Tanllwyth. Event new water fractions are calculated for different percentiles of the discharge regime (in blue, 0-30, 30-60, 60-80, 80-90, and 90-100 for 7-hourly sampling, and 0-20, 20-40, 40-60, 60-80, 80-90, and 90-100 for weekly sampling; percentiles are calculated based only on discharge of time steps with precipitation, and precipitation thresholds were set to $0 \mathrm{~mm} \mathrm{~h}^{-1}$ ). New water fractions of precipitation are calculated for different percentiles of precipitation rates above the precipitation threshold of $0.1 \mathrm{~mm}^{-1}$ (in red, 0-40, 40-60, 60-85, 85-100). Solid and dashed gray lines indicate unweighted and volume-weighted event new water fractions, respectively, across all discharge values. Panels (d)-(f) show event new water fractions, across all discharge values, determined separately for winter (December-February), spring (March-May), summer (June-August), and fall (September-November). Open and solid circles indicate volume-weighted and unweighted event new water fractions, respectively, in (d)-(f).

thus promoting faster transport of precipitation to the stream. In addition, channel networks (Godsey and Kirchner, 2014; Zimmer and McGlynn, 2017) and near-stream saturated zones (Dunne et al., 1991) expand with increasing precipitation, causing raindrops to fall closer to the channel and therefore reach the catchment outlet faster (van Meerveld et al., 2019).

Event new water fractions for the highest $10 \%$ of discharge were somewhat larger than the volume-weighted means (dashed lines in Fig. 10a-c) and about 3 times the unweighted means (solid lines in Fig. 10a-c). During these wet conditions, recent (same-week) precipitation accounted for roughly $25 \%-30 \%$ of streamflow in the weekly samples, and recent (same-7 h) precipitation accounted for roughly $6 \%$ of streamflow in the $7 \mathrm{~h}$ samples. Conversely, event new water fractions for the lowest $40 \%$ of the discharge distributions were typically about half, or less, of the unweighted means. For small water fluxes, new water fractions dropped to less than $5 \%$ in case of weekly time steps, and close to $0 \%$ for 7-hourly sampling. (In Fig. 10a-c, in contrast to the rest of this paper, we used a precipitation threshold of $0 \mathrm{~mm} \mathrm{~h}^{-1}$ when calculating event new water fractions, because a higher precipitation threshold would have excluded most of the low- discharge samples, which mostly coincide with very low precipitation rates. Thus we needed to eliminate the precipitation threshold, to reveal how new water fractions vary across the entire discharge range.) New water fractions of precipitation were also highest during the most intense rain events, and smaller at low precipitation rates. They were always lower than event new water fractions estimated for similar water fluxes, for the reasons outlined in Sect. 5.1.

Volume-weighted event new water fractions were visibly higher in fall and winter compared to spring and summer, and this pattern was mirrored, although less distinctly, in unweighted event new water fractions as well (Fig. 10d-f). This pattern was similar for 7-hourly and weekly sampling, and also for all three catchments. The higher new water fractions during fall and winter may be attributable to higher precipitation and lower evapotranspiration during these months, even though the climate at Plynlimon is generally humid throughout the year, with only slight seasonal differences in precipitation (summer rain accounts for $40 \%$ of annual rainfall; Kirby et al., 1991). A catchment with stronger seasonality in rainfall could potentially exhibit an even more pronounced seasonal pattern in new water fractions. 
Table 2. Comparison of weekly new water fractions ( \pm standard errors) at the Upper Hafren, Lower Hafren, and Tanllwyth.

\begin{tabular}{|c|c|c|c|}
\hline & $\begin{array}{r}\text { Upper Hafren } \\
\text { (from aggregated } \\
\text { 7-hourly sampling) } \\
2007-2009^{\mathrm{a}}\end{array}$ & $\begin{array}{r}\text { Lower Hafren } \\
\text { (from weekly sampling) } \\
2007-2009^{\mathrm{b}}\end{array}$ & $\begin{array}{r}\text { Tanllwyth } \\
\text { (from weekly sampling) } \\
2007-2009^{\mathrm{b}}\end{array}$ \\
\hline \multicolumn{4}{|c|}{ Unweighted weekly new water fractions for all time steps, $Q_{F_{\text {new }}}(\%)$} \\
\hline Deuterium & $5.28 \pm 1.01$ & $3.62 \pm 0.75$ & $4.21 \pm 0.84$ \\
\hline Oxygen-18 & $4.79 \pm 1.11$ & $3.72 \pm 0.90$ & $4.46 \pm 1.01$ \\
\hline \multicolumn{4}{|c|}{ Volume-weighted weekly new water fractions for all time steps, $Q_{F_{\text {new }}^{*}}^{*}(\%)$} \\
\hline Deuterium & $10.88 \pm 1.85$ & $14.92 \pm 3.03$ & $15.18 \pm 2.66$ \\
\hline Oxygen-18 & $9.06 \pm 2.02$ & $16.32 \pm 3.53$ & $16.28 \pm 2.87$ \\
\hline \multicolumn{4}{|c|}{ Unweighted weekly event new water fractions, $Q_{\mathrm{p}} F_{\text {new }}(\%)$} \\
\hline Deuterium & $6.99 \pm 1.34$ & $5.20 \pm 1.07$ & $6.05 \pm 1.20$ \\
\hline Oxygen-18 & $6.34 \pm 1.47$ & $5.35 \pm 1.30$ & $6.41 \pm 1.45$ \\
\hline \multicolumn{4}{|c|}{ Volume-weighted weekly event new water fractions, $Q_{\mathrm{p}} F_{\text {new }}^{*}(\%)$} \\
\hline Deuterium & $11.87 \pm 2.02$ & $16.26 \pm 3.30$ & $16.27 \pm 2.85$ \\
\hline Oxygen-18 & $9.88 \pm 2.20$ & $17.78 \pm 3.85$ & $17.45 \pm 3.08$ \\
\hline \multicolumn{4}{|c|}{ Unweighted weekly new water fractions of precipitation, ${ }^{P} F_{\text {new }}(\%)$} \\
\hline Deuterium & $6.14 \pm 1.18$ & $4.26 \pm 0.88$ & $5.44 \pm 1.08$ \\
\hline Oxygen-18 & $5.56 \pm 1.29$ & $4.38 \pm 1.06$ & $5.76 \pm 1.30$ \\
\hline \multicolumn{4}{|c|}{ Volume-weighted weekly new water fractions of precipitation, ${ }^{P} F_{\text {new }}^{*}(\%)$} \\
\hline Deuterium & $10.14 \pm 1.72$ & $12.74 \pm 2.59$ & $13.96 \pm 2.44$ \\
\hline Oxygen-18 & $8.44 \pm 1.88$ & $13.93 \pm 3.01$ & $14.98 \pm 2.64$ \\
\hline
\end{tabular}

a A synthetic weekly data set for Upper Hafren was created by taking weekly volume-weighted averages of 7-hourly precipitation, and weekly subsamples of 7-hourly Upper Hafren streamwater, at dates and times corresponding to the regular weekly sampling at Lower Hafren and Tanllwyth. ${ }^{b}$ The weekly data sets for Lower Hafren and Tanllwyth were shortened to the period coinciding with the $7 \mathrm{~h}$ sampling at Upper Hafren (also omitting the sampling gap between December 2007 and March 2008).

\subsection{Transit time distributions}

We estimated transit time distributions by ensemble hydrograph separation based on weekly and 7-hourly sampling of oxygen-18. Both transit time distributions of discharge ("backward transit time distributions") and transit time distributions of precipitation ("forward transit time distributions") were low and broad, decreasing gradually at greater lag times, when calculated over all data (solid colored symbols in Fig. 11). Volume-weighted transit time distributions (open gray symbols in Fig. 11) showed somewhat stronger peaks at short lag times, consistent with transport being faster during larger events.

Calculating transit time distributions separately for different seasons, we found a less damped response in fallwinter, compared to spring-summer (Fig. 12). This is consistent with the observation that new water fractions tend to be higher in the colder months (see Fig. 10), possibly due to higher rainfall and lower evapotranspiration, and therefore wetter catchment conditions and higher streamflow, during these months. The seasonal differences between the transit time distributions largely disappeared at lag times longer than about $1-1.5 \mathrm{~d}$. This observation further highlights the likely role of wetter catchment conditions in promoting faster transport of rainwater to the stream during the fall-winter.

\subsection{Comparison with spectral estimates of transit time distributions}

As described in Sect. 4.2, transit time distributions can also be estimated from the power spectra of the tracer time series. The gamma model, when multiplied by the 7-hourly precipitation tracer power spectrum, fitted the streamwater tracer power spectrum closely at timescales of less than roughly 1 month, corresponding to frequencies above roughly 10 per year (Fig. 13a, b). The fitted gamma parameters yielded transit time distributions that corresponded closely to those estimated from ensemble hydrograph separation (Fig. 13c, d). This result is noteworthy, because although both estimation methods obviously relied on the same source data, they involve different mathematical procedures and different underlying assumptions. For example, the spectral fitting method assumed that transit times are gamma-distributed; by contrast, ensemble hydrograph separation makes no assumption about the shape of the transit time distribution, but nonetheless yielded results that are broadly consistent with a gamma 

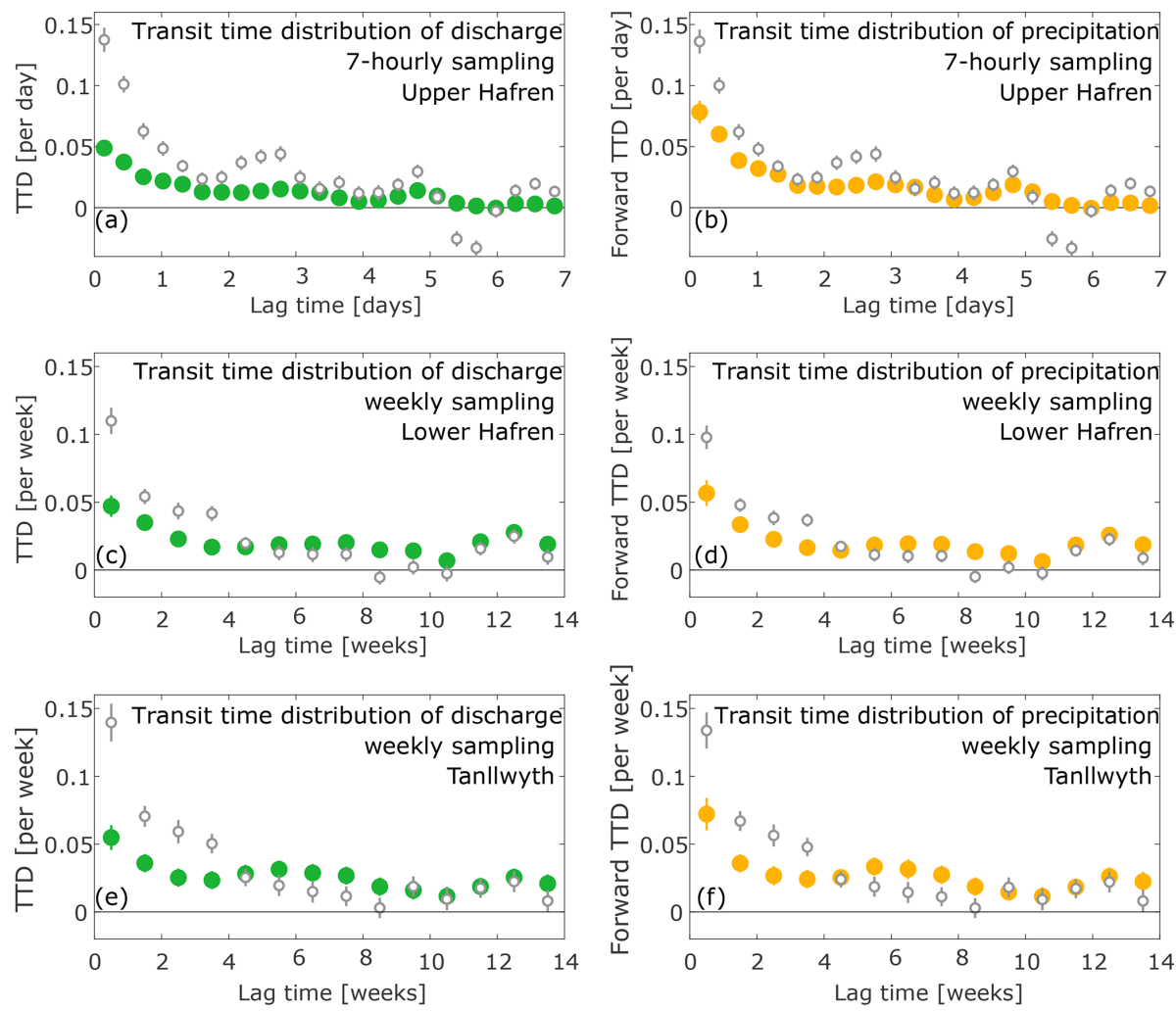

Backward transit time distribution - unweighted
Forward transit time distribution - unweighted

- Volume-weighted transit time distribution

Figure 11. Transit time distributions of discharge ("backward" TTDs, left) and precipitation ("forward" TTDs, right) calculated from 7 hourly $(\mathbf{a}, \mathbf{b})$ and weekly (c-f) time series of oxygen-18. Solid circles indicate unweighted transit time distributions, whereas open gray circles indicate volume-weighted transit time distributions.
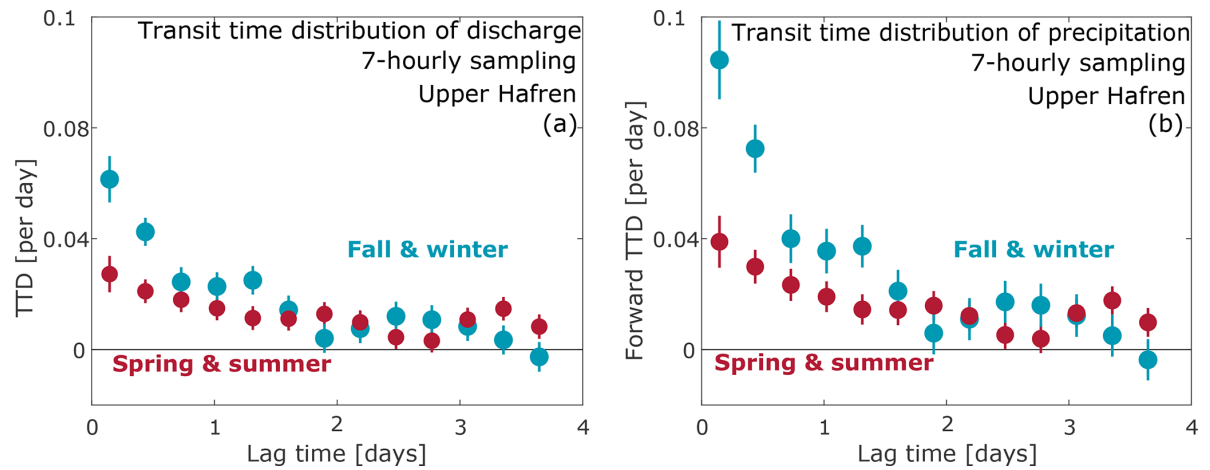

Figure 12. Transit time distributions of discharge ("backward" TTDs, a), and precipitation ("forward" TTDs, b) calculated from 7-hourly oxygen-18 measurements at Upper Hafren for the months of September-February (fall and winter, blue), and March-August (spring and summer, red). Fall-winter TTDs exhibit stronger coupling between precipitation and streamflow than spring-summer TTDs do, over lag times up to 1-1.5 d but not longer. Fall-winter TTDs have larger error bars because there are more gaps in the source data.

distribution. Figure 13 does not provide a strong constraint on the shape of the distribution on timescales much shorter than $7 \mathrm{~h}$ or longer than $7 \mathrm{~d}$. Nonetheless, the similarities between the distributions obtained by spectral fitting and en- semble hydrograph separation strengthen our confidence that both methods can reliably quantify the transit time behavior of real-world catchments. These similarities are not limited to the 7-hourly data shown in Fig. 13; they are also seen, 

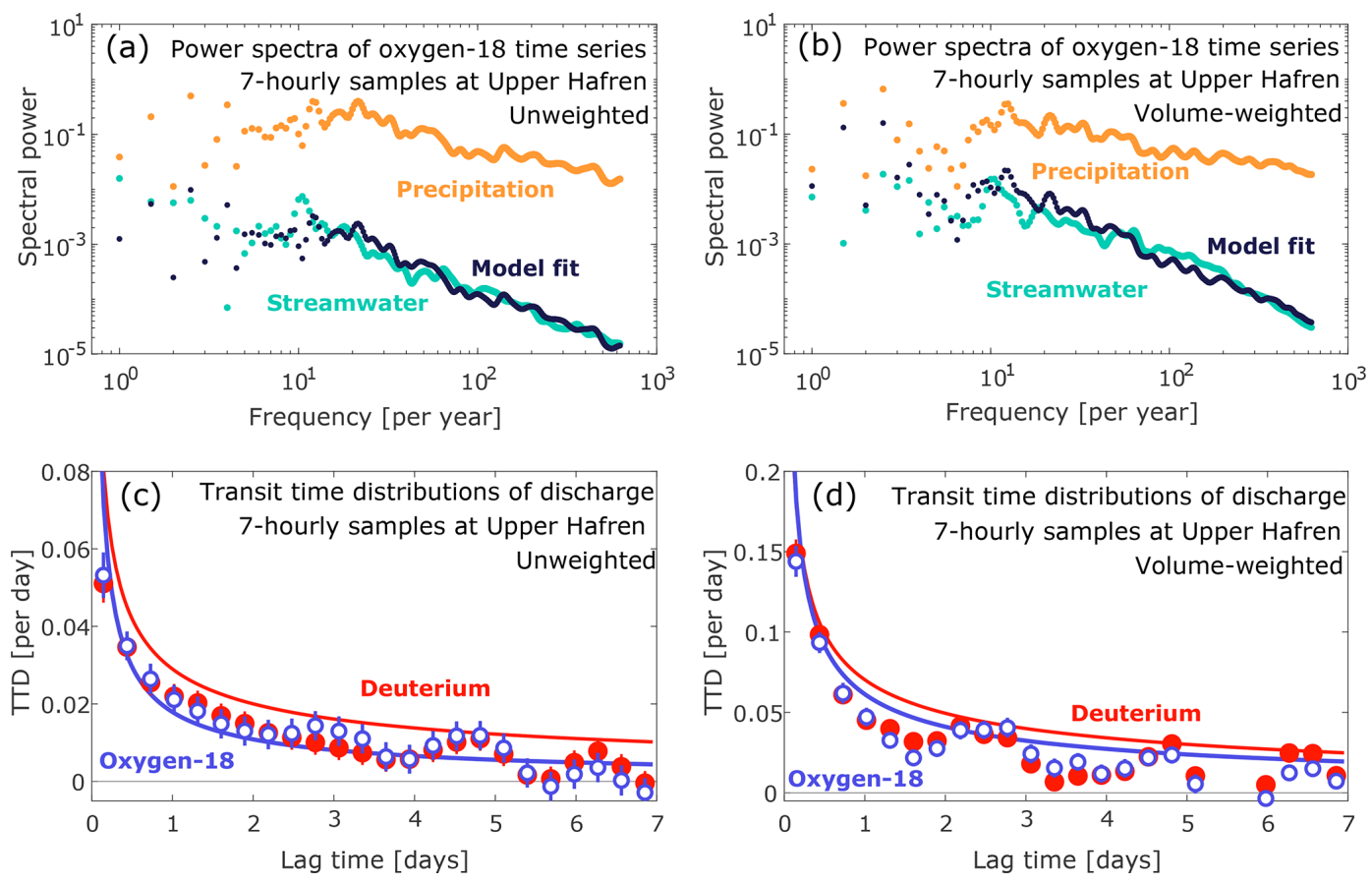

Figure 13. Fits of convolution models to unweighted (a) and volume-weighted (b) power spectra of oxygen-18 in precipitation and streamwater, and gamma distributions estimated by spectral fitting for both deuterium (red lines) and oxygen-18 (blue lines), compared to ensemble hydrograph separation estimates (dots, with standard errors) of unweighted (c) and volume-weighted (d) transit time distributions.

although with greater uncertainties, in the transit time distributions obtained from weekly data at Lower Hafren and Tanllwyth (Figs. S6-S7).

The spectral fitting method assumes that the transit time distribution is time-invariant (i.e., stationary). In theory the regression techniques underlying ensemble hydrograph separation make the same assumption, but the benchmark tests of Kirchner (2019) show that they nonetheless reliably estimate the ensemble averages of nonstationary transit time distributions. Figure 13c, d therefore suggest that the spectral fitting method also yields ensemble averages of nonstationary transit time distributions, but this should be verified using benchmark tests.

The transit time distributions of the two isotopes appeared very similar, both over timescales of days (Fig. 13c, d) and weeks (Figs. S6-S7). Perhaps surprisingly, however, the gamma distributions fitted to the spectra of the two isotopes can yield markedly different estimates of mean transit time (Table S1 in the Supplement). For example, the gamma distribution derived from deuterium in Fig. 13c implied a mean transit time of $0.63 \pm 0.06 \mathrm{yr}$, but the gamma distribution derived from oxygen-18 implied a mean transit time that was 35 -fold longer (22.2 $\pm 4.6 \mathrm{yr})$. The discrepancy was smaller, but still substantial, for the volume-weighted distributions shown in Fig. $13 \mathrm{~d}(0.081 \pm 0.006$ versus $0.140 \pm 0.011 \mathrm{yr}$ for deuterium and oxygen-18, respectively). Across all sites and sampling frequencies, we found that the fitted shape factors $k$ were smaller, the fitted scale factors $\theta$ were larger, and the resulting mean transit times $\bar{\tau}=k \theta$ were longer, when derived from oxygen-18 than from deuterium, with mean transit times typically differing by roughly a factor of 2 . Despite the similarities in the short time behavior of the transit time distributions shown here, their mean transit times are largely determined by their long-time behavior, which is poorly constrained by convolution methods, including the spectral fitting technique used here (and is not estimated at all by ensemble hydrograph separation). Our analysis thus reinforces earlier concerns regarding mean transit times estimated from stable isotope tracers (Stewart et al., 2010; Seeger and Weiler, 2014; Kirchner, 2019), even when, as here, the transit time distribution itself can be reliably estimated over a shorter range of lag times.

Transit time distributions have previously been assessed at Plynlimon from chloride data using StorAge Selection functions. Benettin et al. (2015) calibrated a two-box model to the Plynlimon chloride and hydrometric data and obtained a mean transit time at the Upper Hafren catchment of approximately 1.5 year. Conversely, Harman (2015) used rank StorAge Selection functions at the Lower Hafren, an approach which requires making assumptions about the parametric shape of the transit time distribution. If a gamma distribution was assumed, Harman (2015) found median transit times of 400 and $550 \mathrm{~d}$ for fixed and storage-dependent calculations, respectively. Our approach, on the other hand, depends more directly on data. In spite of these substantially different analyses, we obtained mean transit times that are 
relatively similar to those found by Benettin et al. (2015) and Harman (2015).

Our approach also resulted in similar shapes of the transit time distributions. Benettin et al. (2015) found that the marginal transit time distribution closely resembled a gamma distribution with the shape factor of $k=0.5$, while Harman (2015) obtained a shape factor of $k=0.52$ when enforcing a gamma distribution. This indicates the general plausibility of the underlying shape function, even though the shape factors $k$ obtained from fitting to volume-weighted power spectra in our study varied between 0.40 and 0.54 . These similarities are noteworthy because our approach estimates the short time tail of the transit time distribution directly from tracer data; the shape of the distribution is not specified in advance.

\section{Summary and conclusions}

This study represents the first attempt to assess transport and mixing processes in a real-world catchment using ensemble hydrograph separation. Using this approach, we quantified the contribution of recent precipitation to streamflow in three catchments at Plynlimon, Wales, based on 7-hourly and weekly time series of stable water isotopes. The weekly time series revealed that, on average, roughly $13 \%-15 \%$ of streamwater consisted of precipitation that fell within the previous week, whereas this "new water fraction" decreased to roughly $3 \%$ for $7 \mathrm{~h}$ time steps (Table 1 ). This illustrates that both the numerical value and meaning of "new" water are intrinsically tied to the sampling frequency, because "new" water is defined as streamflow that fell as precipitation during the previous time step.

Our analyses show that the streamflow and precipitation rates strongly influenced the amount of recent precipitation found in streamflow. Larger events yielded larger new water fractions (Fig. 10), indicating that the catchment is more connected during wet conditions, with precipitation inputs being transmitted faster to the catchment outlet. As a consequence, volume-weighted transit time distributions were systematically steeper than unweighted transit time distributions (Fig. 11). Seasonal variations in water fluxes also shaped seasonal patterns of new water contributions to streamflow; new water fractions were higher (Fig. 10), and transit time distributions were steeper (Fig. 12), in the fall-winter months when precipitation was high and evapotranspiration was low, leading to wetter catchment conditions and higher streamflow. These results highlight that the transport of water through catchments is not determined by catchment characteristics alone, but instead by the interaction between catchment characteristics and climatic conditions.

Overall, however, we observed relatively small amounts of recent precipitation in streamflow at Plynlimon, indicating that there is substantial residual storage even when the catchment is relatively dry. This residual storage mixes with most of the incoming precipitation, damping its tracer fluctu- ations. The catchment retains its chemical and isotopic memory because the volume of incoming water is small compared to the substantially larger residual storage. In contrast, only a small fraction of precipitation is transmitted rapidly enough to streamflow that it retains its chemical and isotopic signature.

Transit time distributions estimated from oxygen-18 and deuterium agreed closely with one another, whether calculated by ensemble hydrograph separation or by power spectrum fitting. We also found good agreement between new water fractions calculated from the oxygen-18 and deuterium time series (Tables 1 and 2, Figs. 8 and 9). By aggregating the 7-hourly samples to weekly frequency, we could also show that the differences in weekly new water fractions among the three catchments (Table 2) were consistent with differences in their soil characteristics and in the prevalence of drainage ditches associated with plantation forestry. Together, these findings demonstrate the reliability and utility of the stable water isotope data.

In contrast, weekly new water fractions determined from weekly time series of chloride concentrations were significantly larger than those obtained from time series of stable water isotopes (Table 1, Fig. 8). This may be linked to spatially and temporally variable effects of evapoconcentration and dry deposition of chloride, but the exact extent of these effects is difficult to quantify because all weekly precipitation samples were probably affected to some extent. Identification and removal of dry-deposition-affected samples was easier in the 7-hourly chloride data, and resulted in 7-hourly new water fractions that more closely resembled those derived from stable water isotopes (Table 1, Figs. 8 and 9). Substantial differences still remained, however, and we conclude that stable water isotopes provide a more reliable basis for quantifying catchment transport timescales, especially in the light of novel technology that enables semi-continuous measurements of stable water isotopes in an automated manner (von Freyberg et al., 2017).

The stable isotope measurements presented here cover periods of several months to years at 7-hourly and weekly frequencies, making them some of the longest and most detailed publicly available catchment isotope data sets. They thus provide an opportunity to investigate catchment transport and mixing in great detail, and the analyses presented here can be considered as just a starting point for further work. Moreover, extensive solute data sets are already publicly available for the same sites and sampling periods (Neal et al., 2013c, b; Norris et al., 2017). The data sets of stable water isotopes presented here thus complement the already available data, likely enabling many future analyses of catchment behavior, particularly with respect to catchment-scale reaction processes.

Data availability. The data sets described in this paper are attached as Supplement. The data sets are also archived 
at https://www.envidat.ch/dataset/water-isotopes-plynlimon (doi:10.16904/envidat.82) (Kirchner et al., 2019).

Supplement. The supplement related to this article is available online at: https://doi.org/10.5194/hess-23-4367-2019-supplement.

Author contributions. JWK designed and led the study. CN, AS, and $\mathrm{MN}$ collected and analyzed the isotope samples, JLAK analyzed the data set, and JLAK and JWK prepared the paper with contributions from all authors.

Competing interests. The authors declare that they have no conflict of interest.

Acknowledgements. The authors thank the Plynlimon field staff at the Centre for Ecology and Hydrology (CEH) for their contributions to this work, and Daniele Pezzotta and Stefan Weber for their contributions to the isotopic analyses. We also acknowledge CEH's long-term financial support of the Plynlimon hydrochemistry study, and WSL's support for the isotopic analyses. The first author received an ETH Zurich Postdoctoral Fellowship partly funded by the European Union under the 7th Framework Programme.

Review statement. This paper was edited by Thom Bogaard and reviewed by Markus Hrachowitz and Nigel Roulet.

\section{References}

Bastviken, D., Thomsen, F., Svensson, T., Karlsson, S., Sandén, P., Shaw, G., Matucha, M., and Öberg, G.: Chloride retention in forest soil by microbial uptake and by natural chlorination of organic matter, Geochim. Cosmochim. Ac., 71, 3182-3192, https://doi.org/10.1016/j.gca.2007.04.028, 2007.

Benettin, P., Kirchner, J. W., Rinaldo, A., and Botter, G.: Modeling chloride transport using travel time distributions at Plynlimon, Wales, Water Resour. Res., 51, 3259-3276, https://doi.org/10.1002/2014WR016600, 2015.

Campbell, J., and Green, M.: Water isotope samples from Watershed 3 at Hubbard Brook Experimental Forest, 2006-2010, Environmental Data Initiative, https://doi.org/10.6073/pasta/f5740876b68ec42b695c39d8ad790cee, 2019.

Casper, M. C., Volkmann, H. N., Waldenmeyer, G., and Plate, E. J.: The separation of flow pathways in a sandstone catchment of the Northern Black Forest using DOC and a nested approach, Phys. Chem. Earth, 28, 269-275, https://doi.org/10.1016/S14747065(03)00037-8, 2003.

CEH: National River Flow Archive, Natural Environment Research Council - Center for Ecology \& Hydrology, Wallingford, available at: https://nrfa.ceh.ac.uk, last access: 8 October 2019.

Christophersen, N. and Neal, C.: Linking hydrological, geochemi$\mathrm{cal}$, and soil chemical processes on the catchment scale: an inter- play between modeling and field work, Water Resour. Res., 26, 3077-3086, https://doi.org/10.1029/WR026i012p03077, 1990.

Clark, I. D. and Fritz, P.: Environmental isotopes in hydrogeology, CRC press, Florida, 2013.

Dansgaard, W.: The isotopic composition of natural waters with special reference to the Greenland ice cap, Medd. Groenland, 165, 120, 1961.

Dansgaard, W.: Stable isotopes in precipitation, Tellus, 16, 436468, https://doi.org/10.3402/tellusa.v16i4.8993, 1964

Duffy, C. J. and Gelhar, L. W.: A frequency domain analysis of groundwater quality fluctuations: interpretation of field data, Water Resour. Res., 22, 1115-1128, https://doi.org/10.1029/WR022i007p01115, 1986.

Dunne, T., Zhang, W., and Aubry, B. F.: Effects of rainfall, vegetation, and microtopography on infiltration and runoff, Water Resour. Res., 27, 2271-2285, https://doi.org/10.1029/91WR01585, 1991.

Durand, P., Neal, C., Jeffery, H. A., Ryland, G. P., and Neal, M.: Major, minor and trace element budgets in the Plynlimon afforested catchments (Wales): general trends, and effects of felling and climate variations, J. Hydrol., 157, 139-156, https://doi.org/10.1016/0022-1694(94)90102-3, 1994.

Friedman, L. and Irsa, A. P.: Determination of deuterium in water, Anal. Chem., 24, 876-878, https://pubs.acs.org/doi/10.1021/ac60065a031, 1952.

Godsey, S. and Kirchner, J. W.: Dynamic, discontinuous stream networks: hydrologically driven variations in active drainage density, flowing channels and stream order, Hydrol. Process., 28, 5791-5803, https://doi.org/10.1002/hyp.10310, 2014.

Guan, H., Love, A. J., Simmons, C. T., Makhnin, O., and Kayaalp, A. S.: Factors influencing chloride deposition in a coastal hilly area and application to chloride deposition mapping, Hydrol. Earth Syst. Sci., 14, 801-813, https://doi.org/10.5194/hess-14801-2010, 2010.

Harman, C. J.: Time-variable transit time distributions and transport: Theory and application to storage-dependent transport of chloride in a watershed, Water Resour. Res., 51, 1-30, https://doi.org/10.1002/2014WR015707, 2015.

Heidbüchel, I., Troch, P. A., and Lyon, S. W.: Separating physical and meteorological controls of variable transit times in zero-order catchments, Water Resour. Res., 49, 7644-7657, https://doi.org/10.1002/2012WR013149, 2013.

Hrachowitz, M., Soulsby, C., Tetzlaff, D., Dawson, J. J. C., and Malcolm, I.: Regionalization of transit time estimates in montane catchments by integrating landscape controls, Water Resour. Res., 45, W05421, https://doi.org/10.1029/2008WR007496, 2009.

Hrachowitz, M., Fovet, O., Ruiz, L., and Savenije, H. H.: Transit time distributions, legacy contamination and variability in biogeochemical 1/f $\alpha$ scaling: how are hydrological response dynamics linked to water quality at the catchment scale?, Hydrol. Process., 29, 5241-5256, https://doi.org/10.1002/2015WR017273, 2015.

IAEA: Global Network of Isotopes in Rivers, International Atomic Energy Agency, available at: http://www-naweb.iaea.org/napc/ ih/IHS_resources_gnir.html, last access: 8 October 2019.

IAEA/WMO: Global Network of Isotopes in Precipitation, International Atomic Energy Agency/World Meteorological Organi- 
zation, http://www-naweb.iaea.org/napc/ih/IHS_resources_gnip. html, last access: 8 October 2019.

James, A. and Roulet, N.: Antecedent moisture conditions and catchment morphology as controls on spatial patterns of runoff generation in small forest catchments, J. Hydrol., 377, 351-366, https://doi.org/10.1016/j.jhydrol.2009.08.039, 2009.

Juang, F. H., and Johnson, N. M.: Cycling of chlorine through a forested watershed in New England, J. Geophys. Res., 72, 56415647, https://doi.org/10.1029/JZ072i022p05641, 1967.

Kirby, C., Newson, M., and Gilman, K.: Plynlimon research: the first two decades, Institute of Hydrology, 1991.

Kirchner, J. W.: Aliasing in 1/f $\alpha$ noise spectra: Origins, consequences, and remedies, Physical Review E, 71, 066110, https://doi.org/10.1103/PhysRevE.71.066110, 2005.

Kirchner, J. W.: Quantifying new water fractions and transit time distributions using ensemble hydrograph separation: theory and benchmark tests, Hydrol. Earth Syst. Sci., 23, 303-349, https://doi.org/10.5194/hess-23-303-2019, 2019.

Kirchner, J. W. and Neal, C.: Universal fractal scaling in stream chemistry and its implications for solute transport and water quality trend detection, P. Natl. Acad. Sci. USA, 110, 1221312218, https://doi.org/10.1073/pnas.1304328110, 2013.

Kirchner, J. W., Feng, X., and Neal, C.: Fractal stream chemistry and its implications for contaminant transport in catchments, Nature, 403, 524, https://doi.org/10.1038/35000537, 2000.

Kirchner, J. W., Feng, X., Neal, C., and Robson, A. J.: The fine structure of water-quality dynamics: the (highfrequency) wave of the future, Hydrol. Process., 18, 1353-1359, https://doi.org/10.1002/hyp.5537, 2004.

Kirchner, J. W., Tetzlaff, D., and Soulsby, C.: Comparing chloride and water isotopes as hydrological tracers in two Scottish catchments, Hydrol. Process., 24, 1631-1645, https://doi.org/10.1002/hyp.7676, 2010.

Kirchner, J. W., Knapp, J. L. A., Schlumpf, A., Neal, C., and Neal, M.: Stable water isotopes in precipitation and streamflow at Plynlimon, Wales, UK, EnviDat, https://doi.org/10.16904/envidat.82, 2019.

Leeks, G. J. L. and Marks, S. D.: Dynamics of river sediments in forested headwater streams: Plynlimon, Hydrol. Earth Syst. Sci., 1, 483-497, https://doi.org/10.5194/hess-1-483-1997, 1997.

Lovett, G. M., Likens, G. E., Buso, D. C., Driscoll, C. T., and Bailey, S. W.: The biogeochemistry of chlorine at Hubbard Brook, New Hampshire, USA, Biogeochemistry, 72, 191-232, https://doi.org/10.1007/s10533-004-0357-x, 2005.

Marks, S. D. and Rutt, G. P.: Fluvial sediment inputs to upland gravel bed rivers draining forested catchments: potential ecological impacts, Hydrol. Earth Syst. Sci., 1, 499-508, https://doi.org/10.5194/hess-1-499-1997, 1997.

McGuire, K., DeWalle, D., and Gburek, W.: Evaluation of mean residence time in subsurface waters using oxygen-18 fluctuations during drought conditions in the mid-Appalachians, J. Hydrol., 261, 132-149, https://doi.org/10.1016/S0022-1694(02)00006-9, 2002.

Munksgaard, N., Wurster, C., Bass, A., and Bird, M.: Extreme short-term stable isotope variability revealed by continuous rainwater analysis, Hydrol. Process., 26, 3630-3634, https://doi.org/10.1002/hyp.9505, 2012.

Neal, C. and Rosier, P. T.: Chemical studies of chloride and stable oxygen isotopes in two conifer afforested and moor- land sites in the British uplands, J. Hydrol., 115, 269-283, https://doi.org/10.1016/0022-1694(90)90209-G, 1990.

Neal, C. and Kirchner, J. W.: Sodium and chloride levels in rainfall, mist, streamwater and groundwater at the Plynlimon catchments, mid-Wales: inferences on hydrological and chemical controls, Hydrol. Earth Syst. Sci., 4, 295-310, https://doi.org/10.5194/hess-4-295-2000, 2000.

Neal, C., Reynolds, B., Neal, M., Pugh, B., Hill, L., and Wickham, H.: Long-term changes in the water quality of rainfall, cloud water and stream water for moorland, forested and clear-felled catchments at Plynlimon, mid-Wales, Hydrol. Earth Syst. Sci., 5, 459-476, https://doi.org/10.5194/hess-5-459-2001, 2001.

Neal, C., Reynolds, B., Neal, M., Wickham, H., Hill, L., and Pugh, B.: The impact of conifer harvesting on stream water quality: a case study in mid-Wales, Water Air Soil Poll. 3, 119-138, https://doi.org/10.1023/A:1022104931740, 2003.

Neal, C., Reynolds, B., Neal, M., Wickham, H., Hill, L., and Williams, B.: The impact of conifer harvesting on stream water quality: the Afon Hafren, mid-Wales, Hydrol. Earth Syst. Sci., 8, 503-520, https://doi.org/10.5194/hess-8-503-2004, 2004a.

Neal, C., Reynolds, B., Neal, M., Wickham, H., Hill, L., and Williams, B.: The water quality of streams draining a plantation forest on gley soils: the Nant Tanllwyth, Plynlimon mid-Wales, Hydrol. Earth Syst. Sci., 8, 485-502, https://doi.org/10.5194/hess-8-485-2004, 2004b.

Neal, C., Reynolds, B., Norris, D., Kirchner, J. W., Neal, M., Rowland, P., Wickham, H., Harman, S., Armstrong, L., and Sleep, D.: Three decades of water quality measurements from the Upper Severn experimental catchments at Plynlimon, Wales: an openly accessible data resource for research, modelling, environmental management and education, Hydrol. Process., 25, 3818-3830, https://doi.org/10.1002/hyp.8191, 2011.

Neal, C., Reynolds, B., Rowland, P., Norris, D., Kirchner, J. W., Neal, M., Sleep, D., Lawlor, A., Woods, C., and Thacker, S.: High-frequency water quality time series in precipitation and streamflow: From fragmentary signals to scientific challenge, Sci. Total Environ., 434, 3-12, https://doi.org/10.1016/j.scitotenv.2011.10.072, 2012.

Neal, C., Reynolds, B., Kirchner, J. W., Rowland, P., Norris, D., Sleep, D., Lawlor, A., Woods, C., Thacker, S., and Guyatt, H.: High-frequency precipitation and stream water quality time series from Plynlimon, Wales: an openly accessible data resource spanning the periodic table, Hydrol. Process., 27, 2531-2539, https://doi.org/10.1002/hyp.9814, 2013a.

Neal, C., Kirchner, J., and Reynolds, B.: Plynlimon research catchment high-frequency hydrochemistry data, NERC Environmental Information Data Centre, https://doi.org/10.5285/551a10aeb8ed-4ebd-ab38-033dd597a374, 2013b.

Neal, C., Kirchner, J., and Reynolds, B.: Plynlimon research catchment hydrochemistry, NERC Environmental Information Data Centre, https://doi.org/10.5285/44095e17-43b0-45d4a781-aab4f72da025, 2013c.

Norris, D. A., Harvey, R., Winterbourn, J. M., Hughes, S., Lebron, I., Thacker, S. A., Lawlor, A. J., Carter, H. T., Patel, M., Keenan, P. O., Pereira, M. G., Cosby, B. J., Reynolds, B., Grant, S. J., Pomeroy, I., Hinton, C., Spinney, K., Peters, T. D., and Callahan, B.: Plynlimon research catchment hydrochemistry (2011-2016), NERC Environmental Information 
Data Centre, https://doi.org/10.5285/794c609b-da62-4a42-a4c1$267219865 b b 1,2017$.

Öberg, G.: The natural chlorine cycle - fitting the scattered pieces, Appl. Microbiol. Biot., 58, 565-581, https://doi.org/10.1007/s00253-001-0895-2, 2002.

Remondi, F., Kirchner, J. W., Burlando, P., and Fatichi, S.: Water flux tracking with a distributed hydrological model to quantify controls on the spatio-temporal variability of transit time distributions, Water Resour. Res., 54, 3081-3099, https://doi.org/10.1002/2017WR021689, 2018.

Seeger, S. and Weiler, M.: Reevaluation of transit time distributions, mean transit times and their relation to catchment topography, Hydrol. Earth Syst. Sci., 18, 4751-4771, https://doi.org/10.5194/hess-18-4751-2014, 2014.

Segura, C., James, A., Lazzati, D., and Roulet, N.: Scaling relationships for event water contributions and transit times in smallforested catchments in Eastern Quebec, Water Resour. Res., 48, W07502, https://doi.org/10.1029/2012WR011890, 2012.

Stewart, M. K., Morgenstern, U., and McDonnell, J. J.: Truncation of stream residence time: how the use of stable isotopes has skewed our concept of streamwater age and origin, Hydrol. Process., 24, 1646-1659, https://doi.org/10.1002/hyp.7576, 2010. van Meerveld, H. J. I., Kirchner, J. W., Vis, M. J. P., Assendelft, R. S., and Seibert, J.: Expansion and contraction of the flowing stream network changes hillslope flowpath lengths and the shape of the travel time distribution, Hydrol. Earth Syst. Sci. Discuss., https://doi.org/10.5194/hess-2019-218, in review, 2019.

von Freyberg, J., Studer, B., and Kirchner, J. W.: A lab in the field: high-frequency analysis of water quality and stable isotopes in stream water and precipitation, Hydrol. Earth Syst. Sci., 21, 1721-1739, https://doi.org/10.5194/hess-21-1721-2017, 2017.

Wilkinson, J., Reynolds, B., Neal, C., Hill, S., Neal, M., and Harrow, M.: Major, minor and trace element composition of cloudwater and rainwater at Plynlimon, Hydrol. Earth Syst. Sci., 1, 557-569, https://doi.org/10.5194/hess-1-557-1997, 1997.

Zimmer, M. A. and McGlynn, B. L.: Ephemeral and intermittent runoff generation processes in a low relief, highly weathered catchment, Water Resour. Res., 53, 7055-7077, https://doi.org/10.1002/2016WR019742, 2017. 